\title{
An improved glyoxal retrieval from OMI measurements
}

\author{
L. M. A. Alvarado ${ }^{1}$, A. Richter ${ }^{1}$, M. Vrekoussis ${ }^{2}$, F. Wittrock ${ }^{1}$, A. Hilboll ${ }^{1}$, S. F. Schreier ${ }^{1}$, and J. P. Burrows ${ }^{1}$ \\ ${ }^{1}$ Institute of Environmental Physics (IUP), University of Bremen, Bremen, Germany \\ ${ }^{2}$ Energy, Environment and Water Research Center, The Cyprus Institute, Nicosia, Cyprus
}

Correspondence to: L. M. A. Alvarado (lalvarado@iup.physik.uni-bremen.de)

Received: 17 April 2014 - Published in Atmos. Meas. Tech. Discuss.: 5 June 2014

Revised: 21 October 2014 - Accepted: 29 October 2014 - Published: 3 December 2014

Abstract. Satellite observations from the SCIAMACHY, GOME-2 and OMI spectrometers have been used to retrieve atmospheric columns of glyoxal (CHOCHO) with the DOAS method. High CHOCHO levels were found over regions with large biogenic and pyrogenic emissions, and hot-spots have been identified over areas of anthropogenic activities.

This study focuses on the development of an improved retrieval for $\mathrm{CHOCHO}$ from measurements by the OMI instrument. From sensitivity tests, a fitting window and a polynomial degree are determined. Two different approaches to reduce the interference of liquid water absorption over oceanic regions are evaluated, achieving significant reduction of the number of negative columns over clear water regions. The impact of using different absorption cross-sections for water vapour is evaluated and only small differences are found. Finally, a high-temperature (boundary layer ambient: $294 \mathrm{~K}$ ) absorption cross-section of nitrogen dioxide $\left(\mathrm{NO}_{2}\right)$ is introduced in the DOAS retrieval to account for potential interferences of $\mathrm{NO}_{2}$ over regions with large anthropogenic emissions, leading to improved fit quality over these areas. A comparison with vertical CHOCHO columns retrieved from GOME-2 and SCIAMACHY measurements over continental regions is performed, showing overall good consistency. However, SCIAMACHY CHOCHO columns are systematically higher than those obtained from the other instruments.

Using the new OMI CHOCHO data set, the link between fires and glyoxal columns is investigated for two selected regions in Africa. In addition, mapped averages are computed for a fire event in Russia between mid-July and midAugust 2010. In both cases, enhanced CHOCHO levels are found in close spatial and temporal proximity to elevated levels of MODIS fire radiative power, demonstrating that pyrogenic emissions can be clearly identified in the new OMI CHOCHO product.

\section{Introduction}

Volatile organic compounds (VOC) are chemical species emitted from biogenic, pyrogenic and anthropogenic sources. In spite of their small mixing ratios of usually a few parts per trillion (pptv) to several parts per billion (ppbv), VOC significantly influence the ambient atmospheric composition with direct and indirect impacts on atmospheric chemistry and climate change (Williams, 2004; Curci et al., 2010; Vrekoussis et al., 2010). Enhanced levels of VOC in combination with nitrogen oxides $\left(\mathrm{NO}_{\mathrm{x}}=\mathrm{NO}+\mathrm{NO}_{2}\right)$ lead to the photochemical formation of ozone $\left(\mathrm{O}_{3}\right)$ (e.g. Houweling et al., 1998). Additionally, VOC contribute to the formation of secondary organic aerosols (SOA) (Fu et al., 2008) and to cloud condensation nuclei (CCN) formation (e.g. Yu, 2000).

VOC include non-methane hydrocarbons (NMHC) and oxygenated NMHC (OVOC, e.g. alcohols, aldehydes, organic acids), emitted from various natural and anthropogenic sources such as vegetation, oceans, fossil fuel burning, biomass burning, as well as geochemical processes (Kansal, 2009). On a global scale, biogenic VOC sources (BVOC refers to VOC from biogenic sources) result in an annual release of $1150 \mathrm{TgC} \mathrm{yr}^{-1}$ (Guenther et al., 1995), mainly emitted in the form of isoprene $\left(\mathrm{C}_{5} \mathrm{H}_{8}\right)$ and monoterpenes (varieties of molecules with two isoprene units) (Guenther et al., 1995; Atkinson and Arey, 2003; Kansal, 2009). However, the uncertainties in total emissions are high since the amounts emitted depend on several parameters, including the plant species, temperature, humidity, and also the condition of the plant (Guenther et al., 2000). In urban areas, VOC from anthropogenic emissions (AVOC) are emitted from mobile and stationary sources (Kansal, 2009). However, estimated AVOC emissions of $161 \mathrm{Tg} \mathrm{Cyr}^{-1}$ are lower than the respective BVOC. Lastly, $49 \mathrm{Tg} \mathrm{Cyr}^{-1}$ emanate from pyrogenic emissions (Andreae and Merlet, 2001). Similar to the 
biogenic and anthropogenic emissions, the total amount of pyrogenic emissions of VOC is largely uncertain (Stavrakou et al., 2009b).

The inhomogeneous spatial and temporal distribution of VOC, resulting in a large variability of VOC fluxes into the atmosphere, led several research groups to study the global distribution of smaller molecules such as formaldehyde (HCHO) and $\mathrm{CHOCHO}$, which are produced from precursor BVOC and AVOC species. Also pyrogenic emissions can produce $\mathrm{HCHO}$ and $\mathrm{CHOCHO}$ both directly and indirectly. CHOCHO, the smallest of the alpha-dicarbonyls and one of the most prevalent carbonyls in the atmosphere (Myriokefalitakis et al., 2008), is often used as a tracer of hydrocarbons over areas with enhanced VOC emissions, the socalled photochemical "hot-spot" regions. CHOCHO is an intermediate product in the oxidation of most VOC (Volkamer et al., 2005a; Wittrock, 2006; Sinreich et al., 2007) and an indicator of secondary organic aerosol (SOA) formation (Sinreich et al., 2007; Fu et al., 2008; Vrekoussis et al., 2009). Glyoxal is mainly produced from the oxidation of isoprene, acetylene and aromatic hydrocarbons (Fu et al., 2008; Liu et al., 2012) and has a short atmospheric lifetime on the order of a few hours (Atkinson, 2000), with photolysis being its dominant sink (Tadić et al., 2006). Other sinks comprise wet and dry deposition (Fu et al., 2008), SOA formation (Volkamer et al., 2007, and references therein), and the oxidation mechanism, which is driven by the presence of hydroxyl radicals (Setokuchi, 2011).

In recent years, measurements from spaceborne instruments, including the SCanning Imaging Absorption spectroMeter for Atmospheric CHartographY (SCIAMACHY) (Burrows et al., 1995; Bovensmann et al., 1999), the second Global Ozone Monitoring Experiment (GOME-2) (Callies et al., 2000), and the Ozone Monitoring Instrument (OMI) (Levelt et al., 2006) have been used to derive the spatial distribution of $\mathrm{CHOCHO}$ at global scale by applying the Differential Optical Absorption Spectroscopy (DOAS) method (Platt and Stutz, 2008) in the visible spectral region. Wittrock et al. (2006) have first derived the spatial distribution of CHOCHO vertical columns from SCIAMACHY observations whilst a few years later, Vrekoussis et al. (2009) presented a long-term study of its spatial and temporal variability. One year later, Vrekoussis et al. (2010) and Lerot et al. (2010) reported on the first GOME-2 retrievals of CHOCHO columns. Vrekoussis et al. (2010) used the ratio of collocated $\mathrm{CHOCHO}$ and $\mathrm{HCHO}$ vertical columns to classify various VOC sources, whereas Lerot et al. (2010) presented for the first time a retrieval algorithm with a two-step approach to reduce interferences in the $\mathrm{CHOCHO}$ analysis over some oceanic regions caused by liquid water absorption. The latter approach resulted in an improvement of the fit quality and less negative $\mathrm{CHOCHO}$ columns over clear water regions. Kurosu et al. (2007) presented a first glyoxal product based on OMI data and compared global maps for different seasons. All studies found that glyoxal can have high values over tropical and sub-tropical regions, mainly over regions with biomass burning and biogenic activities. In addition, several hot-spots were identified over areas of anthropogenic activities and over tropical oceans, the latter suggesting a potential "unknown" source of CHOCHO.

In this study, results of an improved CHOCHO DOAS retrieval applied to the radiances measured by the OMI instrument are presented. Sensitivity tests have been performed aiming at the optimization of the $\mathrm{CHOCHO}$ retrieval parameters, and at reducing spectral interferences with liquid water absorption over ocean regions and with tropospheric $\mathrm{NO}_{2}$ absorption over areas with large $\mathrm{NO}_{\mathrm{x}}$ emissions.

Section 2 of the paper includes a description of the satellite instrument, the retrieval approach used to obtain the atmospheric CHOCHO columns based on analysis of relevant sensitivity tests, and a description of the method used to limit interferences with liquid water absorption over ocean and with $\mathrm{NO}_{2}$ absorption over regions with large $\mathrm{NO}_{\mathrm{x}}$ emissions, as well as evaluation of the impact of different water vapour absorption cross-sections in the glyoxal retrieval. Section 3 presents a detailed comparison of the annual cycle of glyoxal vertical columns, retrieved with the new OMI algorithm, with SCIAMACHY and GOME-2 over selected regions of interest. In Sect. 4, seasonal maps of OMI glyoxal are presented. In the last section, the OMI glyoxal product is used to investigate the link between $\mathrm{CHOCHO}$ columns and biomass burning in Africa as well as during the massive fire event in Russia in 2010.

\section{Methods}

\subsection{The OMI instrument}

The Ozone Monitoring Instrument on board NASA's Aura satellite is a nadir-viewing imaging spectrograph that measures backscattered radiation in the wavelength range from 270 to $500 \mathrm{~nm}$ with a spectral resolution between 0.42 and $0.63 \mathrm{~nm}$ and a spectral sampling of between 0.15 and $0.32 \mathrm{~nm}$. The instrument's spatial resolution is $13 \mathrm{~km} \times 24 \mathrm{~km}$ at nadir and towards the scan edges the pixels become significantly larger across-track. OMI has a swath that provides global coverage in one day (14 orbits) (Levelt et al., 2006), overpasses the equator at 13:45 LT, and has been recording data since October 2004.

\subsection{Glyoxal retrieval}

The DOAS method, based on absorption spectroscopy, allows the determination of atmospheric amounts of trace gases with narrow absorption bands in the ultraviolet (UV) and visible regions of the electromagnetic spectrum. The method analyses the intensity of the absorption bands using the Beer-Lambert law (Platt and Stutz, 2008, and references therein). The DOAS technique is based on the separation of high- and low-frequency variations in the absorption 
spectrum (optical depth spectra). The latter, together with Rayleigh and Mie scattering, are removed by a low-order polynomial. The narrow absorption bands are used to retrieve the trace gas slant column densities (SCs) by including corresponding absorption cross-sections in the DOAS fit. SCs represent the amount of the absorbing trace gas integrated along the effective light path in the atmosphere and can be determined by a non-linear least-squares method.

For the retrieval of weak absorbers such as $\mathrm{CHOCHO}$, an appropriate selection of the fitting window is a prerequisite for deriving accurate SCs. Most retrievals focus on avoiding spectral regions where interfering species have significant absorption lines. Retrievals of $\mathrm{CHOCHO}$ are usually performed in the spectral window between 420 and $460 \mathrm{~nm}$, with polynomial of order 2, 3 or 4 for removal of broad-band signatures, and including the respective interfering species (Wittrock et al., 2006; Vrekoussis et al., 2009). As mentioned above, Lerot et al. (2010) showed that absorption by liquid water interferes with $\mathrm{CHOCHO}$ retrievals over oceans, and a pre-fitting of the liquid water signature using a larger fitting window was suggested to improve the $\mathrm{CHOCHO}$ retrievals. Despite these efforts to achieve better $\mathrm{CHOCHO}$ retrievals, the results are still affected by large uncertainties. Here, we present a new retrieval algorithm for the OMI measurements based on detailed sensitivity tests.

A two-step wavelength calibration has been applied which first aligns the irradiance spectrum to a high-resolution Fraunhofer spectrum (Chance and Kurucz, 2010) and then the radiance spectrum to the irradiance. An intensity offset is fitted as well. Additionally, the quality flags provided by NASA are used to reduce the problem with the row anomaly.

The additional settings used in the glyoxal retrievals within this study are described in detail below.

\subsection{Reference absorption cross sections}

The reference absorption cross-sections used in the retrieval include CHOCHO (Volkamer et al., 2005b) as well as the interfering species. In the wavelength range of $420-460 \mathrm{~nm}$, interferences with $\mathrm{O}_{3}$ (Bogumil et al., 2003), $\mathrm{NO}_{2}$ (Vandaele et al., 1998), $\mathrm{O}_{4}$ (Thalman and Volkamer, 2013), water vapour (Rothman et al., 2005) and liquid water (Pope and Fry, 1997) can be found. Moreover, a synthetic ring spectrum (Vountas et al., 1998) accounting for the Ring effect is included. All absorption cross-sections were convoluted to OMI's spectral resolution taking into account the variation of slit function across the charge-coupled device (CCD).

\subsection{Dependence on the fitting window}

Systematic errors can be introduced into the glyoxal retrieval by possible cross-correlations between reference cross-sections, by the influence of instrumental features, and by shifts in the wavelength calibration. Thus, a dependence on the fitting window can be observed in the retrieved
CHOCHO SCs, because all these systematic errors exhibit a dependency on the wavelength interval.

In order to test the sensitivity of the retrieval on the wavelength interval selected and to find an appropriate fitting window for the CHOCHO retrieval, a synthetic measurement spectrum of backscattered Earthshine was computed using the radiative transfer model SCIATRAN (Rozanov et al., 2013). A satellite measurement in nadir geometry, at solar zenith angle of $41^{\circ}$, and at constant surface reflectance of $5 \%$ was simulated in the wavelength range of $365-500 \mathrm{~nm}$ at a spectral sampling of $0.2 \mathrm{~nm}$. Absorption cross-sections of $\mathrm{CHOCHO}$ and interfering species $\left(\mathrm{NO}_{2}, \mathrm{O}_{3}, \mathrm{H}_{2} \mathrm{O}_{\text {vap }}\right.$, and $\mathrm{O}_{4}$ ), degraded to the OMI resolution, were used to model absorption processes in the light path. However, no Ring effect was simulated in the model. For the atmospheric profiles, the assumption was made of a $\mathrm{CHOCHO}$ concentration profile, exponentially decreasing with altitude, and no stratospheric contribution. The sensitivity test consists of retrievals of glyoxal SCs in different wavelength intervals. The results are shown in Fig. 1 (top), where each pixel corresponds to one CHOCHO SC retrieved using one particular wavelength range and is colour coded according to the relative difference between the retrieved and a priori $\mathrm{SC}\left(2.69 \times 10^{15} \mathrm{molec}^{-2}\right)$. The wavelength intervals have start limits of $420-437 \mathrm{~nm}$, end limits of $442-460 \mathrm{~nm}$, the limits have steps of $0.2 \mathrm{~nm}$, and a polynomial of order 3 is used in the retrievals. This test follows the method developed in Vogel et al. (2013).

In general, the observed deviations are mostly rather small (i.e. $<4 \%$ ). The largest deviations are found for wavelength ranges with start limits between $420-430 \mathrm{~nm}$ and end limits of $442-430 \mathrm{~nm}$, which correspond to the wavelength region, where glyoxal only has weak absorption bands and consequently the interference with the strong absorbers (e.g. $\mathrm{NO}_{2}$ and $\mathrm{O}_{3}$ ) is more significant. These deviations decrease for start and end wavelengths in the ranges 430-437 and 448$454 \mathrm{~nm}$, respectively, as these ranges include an additional glyoxal band with greater absorption than found between 420-430 nm. Nevertheless, interferences with the absorption bands of $\mathrm{NO}_{2}, \mathrm{O}_{3}, \mathrm{O}_{4}$ and $\mathrm{H}_{2} \mathrm{O}_{\text {vap }}$ are present in these wavelength ranges, the last two being the dominant species. Consequently, the deviations decrease when the strongest absorption band of glyoxal is included, the most accurate retrievals being found in the wavelength intervals with start limits of $430-436 \mathrm{~nm}$ and end limits of $456-460 \mathrm{~nm}$. Thus, the best wavelength intervals for the retrieval of glyoxal from synthetic spectra simulated for the specific scenario described above, have start limits of 430-436 nm and end limits of 456$460 \mathrm{~nm}$, corresponding to deviations close to zero from the a priori SC. In Fig. 1 (bottom), the blue lines mark these start limits and the green lines the end limits.

To compare these results with real data, a similar test was performed for selected relatively small areas over Africa, Europe, North America (NA), Brazil, a desert region, and an oceanic area (see Table 1). These regions were selected to 


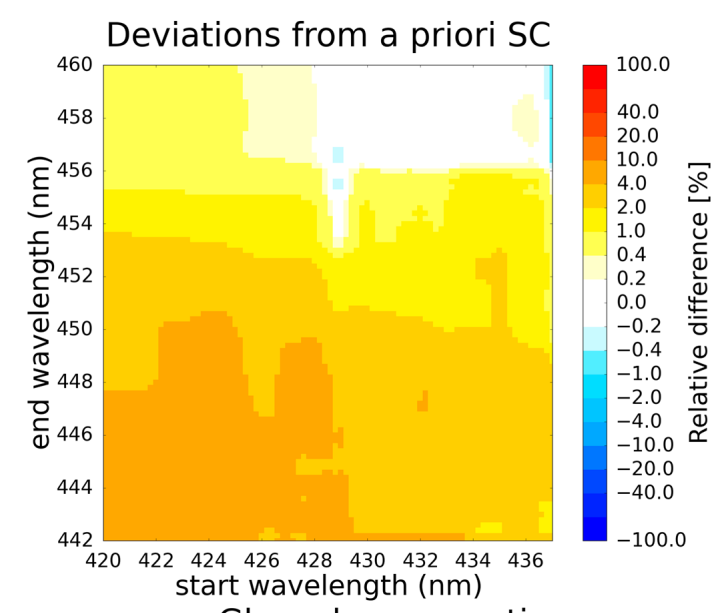

Glyoxal cross-section

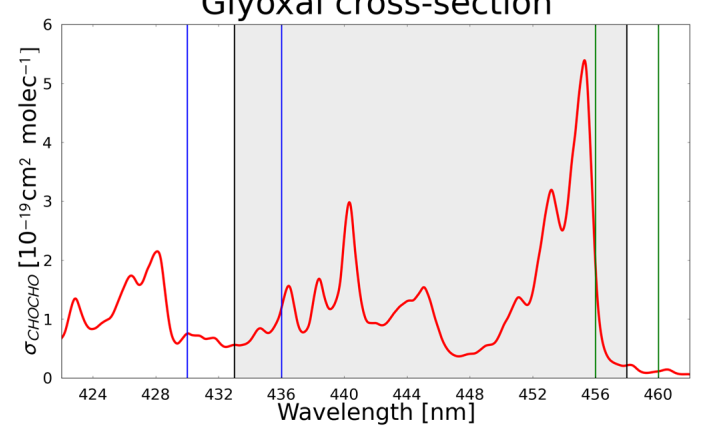

Figure 1. Colour mapping of the relative difference of $\mathrm{CHOCHO}$ SCs with respect to the a priori ("true value") $\left(\frac{\mathrm{SC}_{\text {fitted }}-\mathrm{SC}_{\text {true }}}{\mathrm{SC}_{\text {true }}} \times 100\right)$ retrieved from a synthetic spectrum for wavelength intervals with start limits of $420-437 \mathrm{~nm}$ and end limits $442-460 \mathrm{~nm}$ (top). Glyoxal absorption cross-section at $296 \mathrm{~K}$ (Volkamer et al., 2005b); blue and green lines mark the start and end of the favourable wavelength intervals, respectively, with the main absorption bands in the shaded area (bottom).

be representative for different $\mathrm{CHOCHO}$ levels and sources, as well as for possible interfering effects (sand, liquid water absorption). For each region, more than 100 spectra were included to obtain significant results and to limit the effect of measurement noise (with SC detection limits between $0.5 \times 10^{14}$ molec cm $^{-2}$ and $2.0 \times 10^{14} \mathrm{molec} \mathrm{cm}^{-2}$ ). The retrieval settings were identical to the synthetic test described above; additionally, the Ring cross-section and an intensity offset were included. Figure 2 shows averages of the retrieved SCs for each region and for all wavelength ranges. The variation in retrieved SCs is large on real data for all regions selected, highlighting the fact that glyoxal retrievals are very sensitive to details of the fitting parameters selected. A similar variability in the results is found for ground-based data as well as for SCIAMACHY and GOME-2 measurements (not shown), but the observed pattern of deviations varies. This indicates that both interference between absorption from different absorbers and also instrumental effects may play a role. In the absence of validation data, the true
Table 1. Regions selected for Fig. 2.

\begin{tabular}{lccr}
\hline & Latitude $\left[{ }^{\circ}\right]$ & Longitude $\left[{ }^{\circ}\right]$ & Date \\
\hline Africa & $-5.0 \pm 3.0$ & $13.5 \pm 0.5$ & 9 Aug 2007 \\
Brazil & $-8.5 \pm 3.5$ & $-64.5 \pm 2.5$ & 19 Aug 2007 \\
Europe & $49.5 \pm 3.5$ & $7.0 \pm 5.0$ & 20 Aug 2007 \\
NA & $31.0 \pm 3.0$ & $-82.5 \pm 1.5$ & 14 Aug 2007 \\
Desert & $22.0 \pm 3.0$ & $20.0 \pm 4.0$ & 15 Aug 2007 \\
Ocean & $25.0 \pm 1.0$ & $144.0 \pm 1.0$ & 1 Aug 2007 \\
\hline
\end{tabular}

columns are not known for this test on real data. However, some consistency considerations can help to make a choice for the fitting range. First, the strongest absorption band of glyoxal should be included in the fitting window, because without this band, interferences with other species in the wavelength range of weak glyoxal absorption bands (420$450 \mathrm{~nm}$ ) are stronger and sometimes lead to unphysical results. This restricts our intervals to start wavelengths of 420 $437 \mathrm{~nm}$ and end wavelengths of $456-460 \mathrm{~nm}$. Second, the SC means obtained over the desert in the restricted region are mostly negative for start wavelengths below $432 \mathrm{~nm}$ (larger fitting windows, Fig. 2), most likely due to soil interferences (Richter et al., 2011). However, over the Sahara fits using start limits between 432 and $437 \mathrm{~nm}$ show mean values close to zero, which is realistic because under normal circumstances, no CHOCHO can be expected in the desert atmosphere. Then, the chosen wavelength intervals can be restricted again to start limits between 432 to $437 \mathrm{~nm}$ and end limits between 456 to $460 \mathrm{~nm}$, which also show homogeneous patterns for Africa, Brazil, Europe, and the NA region within the chosen wavelength ranges and also have limits similar to the wavelength ranges obtained from the synthetic spectrum. However, over the ocean region, negative SC means are obtained, probably as a consequence of interference with liquid water absorption (Lerot et al., 2010). Additionally, the fitting windows used for glyoxal retrievals in previous studies are found in these chosen wavelength intervals (Vrekoussis et al., 2010; Lerot et al., 2010). Despite the good consistency found for OMI data over the selected regions, the glyoxal retrieval appears to be sensitive to small changes in wavelength and it is a challenge to determine the most appropriated fitting window.

In the following, we will use a fitting window extending from 433 to $458 \mathrm{~nm}$ (within the chosen wavelength intervals), as indicated by the shaded area in Fig. 1 (bottom), which is slightly larger than the fitting windows used in previous studies (e.g. Vrekoussis et al., 2010). In addition, when the liquid water cross-section is included in the glyoxal retrieval (see Sect. 2.6), a reduction in the number of negative glyoxal SCs is observed over ocean in this wavelength range in comparison to a smaller fitting window (e.g. 434$458 \mathrm{~nm}$ ). This wavelength range covers the strong $\mathrm{CHOCHO}$ absorption bands, which have already been used to retrieve 

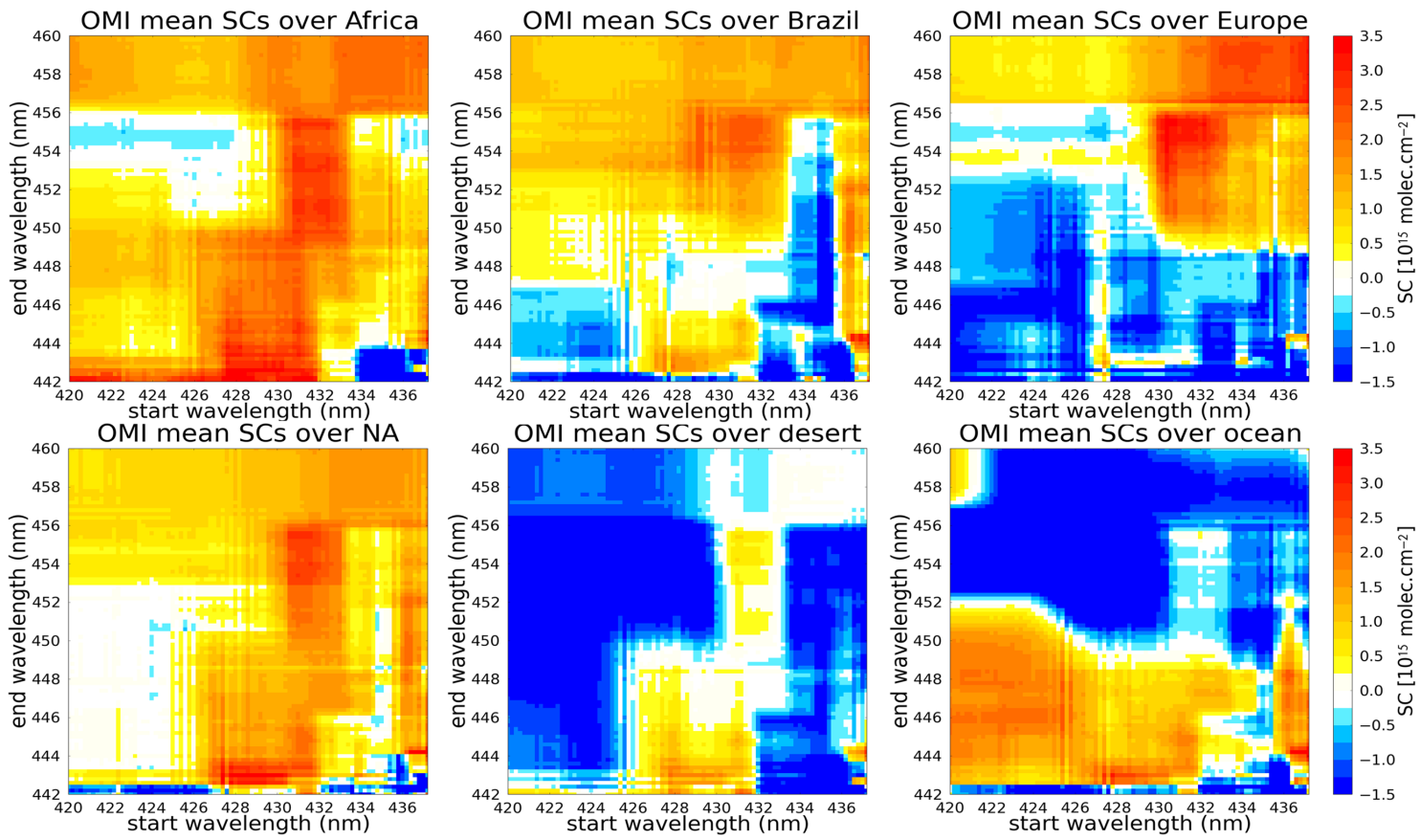

Figure 2. CHOCHO SC means retrieved over selected regions from OMI measurements for wavelength windows with start limits of 420 $437 \mathrm{~nm}$ and end limits of 442-460 nm, during different days on August 2007 (see Table 1).

glyoxal from ground-based and ship-based instruments (Sinreich et al., 2007, 2010) as well as from satellite data (Wittrock et al., 2006; Vrekoussis et al., 2009, 2010; Lerot et al., 2010).

\subsection{Dependence on the polynomial order}

Another main parameter in the DOAS retrieval is the order of the polynomial accounting for the broadband features in the measured spectra. Experience shows that a low-order polynomial helps to avoid instability in the fit, while increasing the degree usually improves the fitting residual, in particular for large fitting windows. In order to evaluate the dependence of the fit results on the polynomial degree, the glyoxal retrievals were performed for both cases (i.e. using the synthetic spectrum and real data) for polynomial orders 2 , 3 and 4. For the synthetic spectrum, Fig. 3 (top) shows the deviations of the CHOCHO SCs from the a priori SC, for polynomial degrees 2, 3 and 4 . For the specific conditions of the simulated spectrum, the results are similar for polynomial orders 3 and 4, while the SCs retrieved with polynomial order 2 show larger deviations from the true value for most wavelength intervals and more variability for the wavelength ranges where the deviations are close to zero for the polynomial orders 3 and 4 .

For comparison, glyoxal columns from OMI measurements over two small regions (Africa and North America) have been retrieved for August 2007, as high glyoxal levels are expected over these areas in summer, which are attributed to biogenic activity and biomass burning. Figure 3 (middle and bottom) shows similar patterns for polynomial order 3 in both regions and a more homogeneous behaviour than polynomial order 4 for the chosen wavelength ranges, while results using polynomial degree 2 show more variability in the $\mathrm{CHOCHO} \mathrm{SCs}$ for the wavelength area of interest. Despite of similar results for polynomial degree 3 and 4, in the following a polynomial order of 3 is selected in order to keep the degrees of freedom in the retrieval low and the consistency between regions high.

\subsection{Interference with liquid water absorption}

One of the main problems in glyoxal retrievals found by Vrekoussis et al. (2009) was the negative CHOCHO SC values over the remote Pacific Ocean, possibly due to interferences with the absorption by liquid water. Later, similar results were found by Lerot et al. (2010), which proposed a two-step retrieval to reduce the negative values over ocean regions. In a first step, they retrieved liquid water SCs from a large fitting window $(405-490 \mathrm{~nm})$. In a second step, they then retrieved glyoxal SCs in the wavelength range of 435$460 \mathrm{~nm}$, fixing the liquid water SC to the results from the first step. This method worked well for GOME-2 fits, significantly reducing the impact of liquid water absorption on the glyoxal fits. Similar problems of interferences over ocean regions were found in the glyoxal retrieval from OMI measurements. 

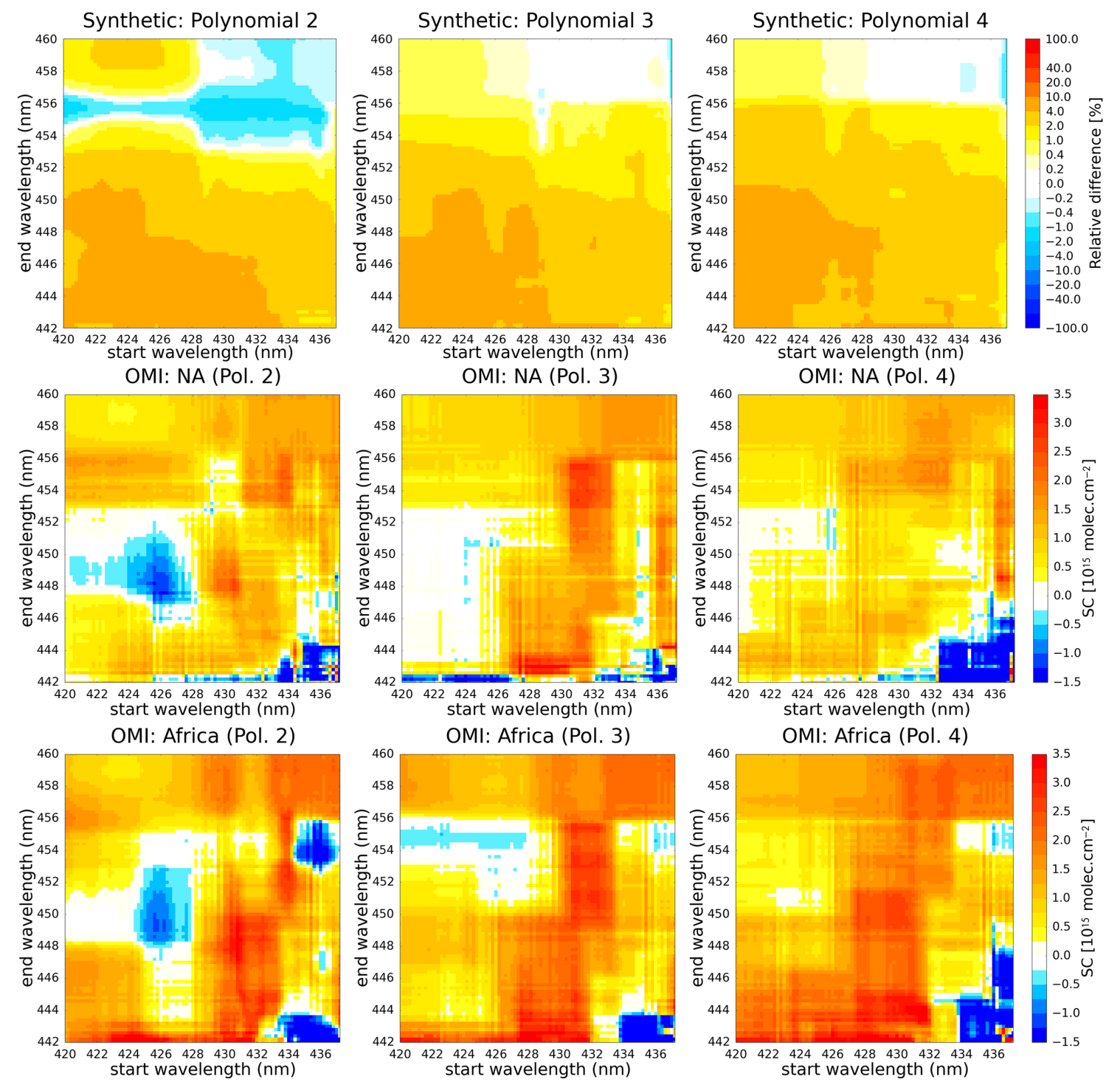

Figure 3. Colour mapping of CHOCHO SC deviation with respect to the a priori ("true value"), retrieved from a synthetic spectrum for wavelength intervals with start limits of $420-437 \mathrm{~nm}$, end limits $442-460 \mathrm{~nm}$, and polynomial degrees 2 , 3 and 4 (top). CHOCHO SC means retrieved over Africa and North America for August 2007 (see Table 1) from OMI measurements for different wavelength ranges and polynomial orders (middle and bottom).

In order to reduce the number of negative glyoxal SCs over the remote Pacific Ocean, two different approaches were tested. First, we followed the approach by Lerot et al. (2010) and introduced a two-step fitting procedure, where the absorption by liquid water is determined in a pre-fit using a wavelength range of $410-495 \mathrm{~nm}$. However, the two-step approach was only applied over water bodies, as no liquid water interferences are expected over land. In a second test, a liquid water absorption cross-section was introduced in the standard DOAS fit for measurements over ocean regions. Figure 4 shows a comparison of monthly global maps of CHOCHO SCs for August 2007 (top) and CHOCHO $\mathrm{SC}$ means retrieved over a small oceanic region (latitude: $25.0^{\circ} \pm 1.0^{\circ}$; longitude: $144.0^{\circ} \pm 1.0^{\circ}$ ) for different wavelength intervals (bottom).

All three maps show a similar pattern over ocean, with negative values of varying amplitude over clear water regions. Clearly, SCs obtained from the standard retrieval without liquid water absorption cross-section have more negative results over oceans than the two retrievals that add this cross-section. As can be seen from the maps showing the dependence on fitting window, the two-step approach reduces the number of negative glyoxal SCs and varies between $-2.5 \times 10^{14}$ and $2.5 \times 10^{14}$ molec cm $^{-2}$ (white area). In the fitting window chosen in earlier tests, the retrievals over the ocean are close to 0 when fitting the liquid water 

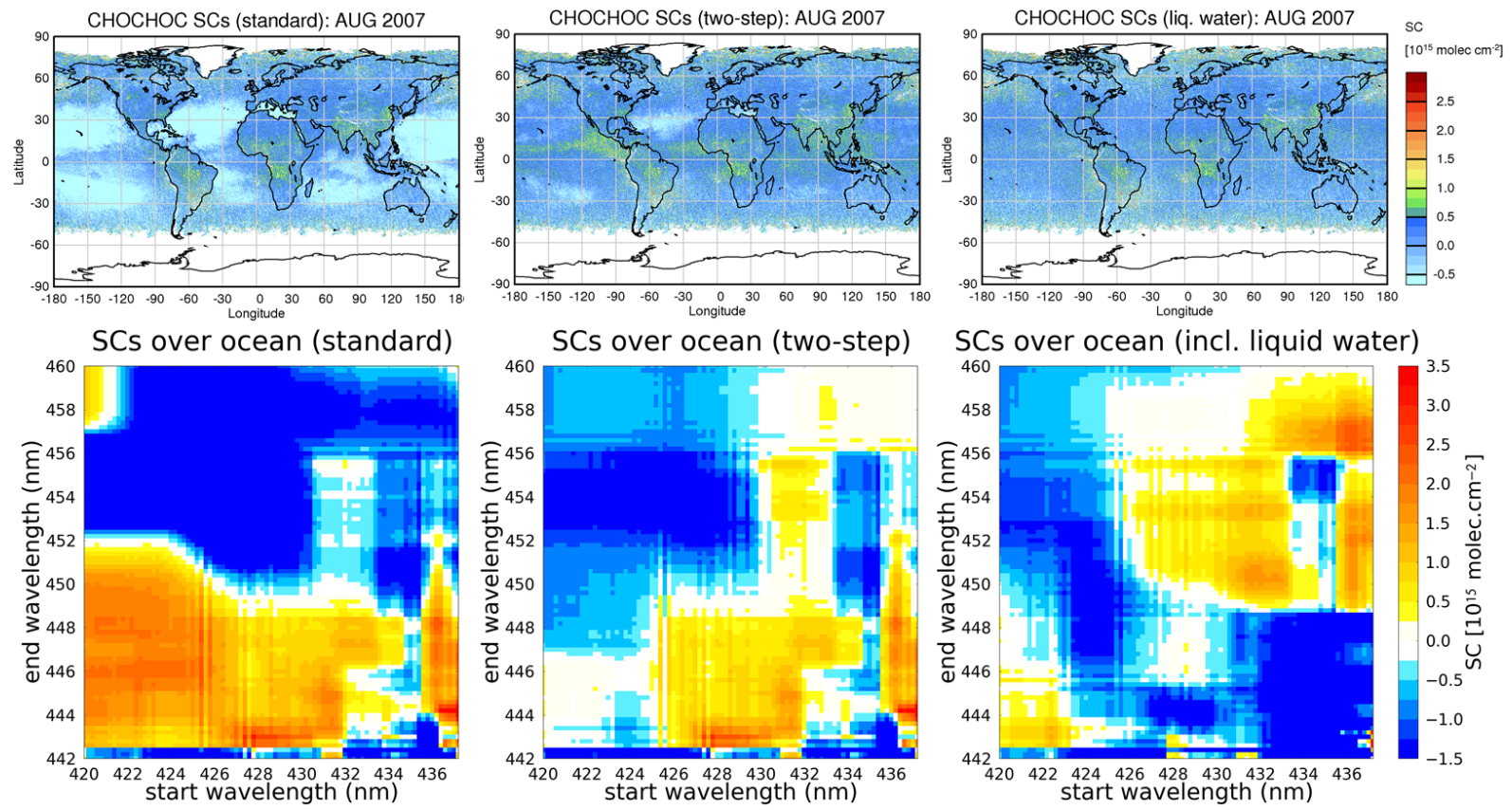

Figure 4. Maps of monthly averaged glyoxal slant columns retrieved from OMI measurements for August 2007 (top). Cloud screening has been applied in all maps (see Sect. 3). CHOCHO SCs obtained using the standard CHOCHO retrieval without liquid water absorption crosssection (left), by using the two-step fit (centre), and including the liquid water absorption cross-section in the standard $\mathrm{CHOCHO}$ retrieval (right). CHOCHO SC means retrieved over ocean (latitude: $25.0^{\circ} \pm 1.0^{\circ}$; longitude: $144.0^{\circ} \pm 1.0^{\circ}$ ) from OMI measurements for the three different retrievals on 1 August 2007 (bottom).

cross-section (see Fig. 4, top right). Based on the global behaviour, the smallest number of negative values is obtained when including the liquid water cross-section directly in the fit, and therefore this option was selected for the final data product.

Although the CHOCHO SCs retrieved by including the liquid water cross-section are improved over the oceans, the interference with liquid water is still present to a lesser degree, judging from the fact that some regions with negative CHOCHO SC values still remain. Whether this is the result of non-optimal cross-sections for liquid water (Peters et al., 2014) or other effects such as vibrational Raman scattering in the ocean cannot be decided at this point.

\subsection{Interference with $\mathrm{NO}_{2}$ absorption}

Some urban and industrial regions show high levels of glyoxal (e.g. the large urban agglomerations Johannesburg, Los Angeles, Beijing, and Guangzhou) due to the production of $\mathrm{CHOCHO}$ from aromatics and acetylene (Volkamer et al., 2007; Myriokefalitakis et al., 2008; Liu et al., 2012). However, the observed signal could potentially also be influenced by spectral interferences with tropospheric $\mathrm{NO}_{2}$, which is very abundant in these regions (see Fig. 5, top). To test this, an additional $\mathrm{NO}_{2}$ absorption cross-section measured at high temperature (i.e. typical surface, $294 \mathrm{~K}$ ) was included in the glyoxal retrieval to better represent near-surface $\mathrm{NO}_{2}$.
Monthly maps of glyoxal SCs for September 2007 are shown in Fig. 5. Including the high-temperature $\mathrm{NO}_{2}$ absorption cross-section in the fit leads to decreased glyoxal SC values over pollution hot-spots and improves the fitting residuals. The improvement of chi-square values over these regions is up to $5 \%$ and even larger in some cases. However, glyoxal values still remain high in all cases, indicating that the observed enhancements are not artefacts but rather indicate genuine anthropogenic sources.

To further investigate the effect of including the hightemperature cross-section of $\mathrm{NO}_{2}$, a comparison between the glyoxal seasonal variation including and excluding the term is presented in Fig. 6 (top) for the regions of Beijing (latitude: $37.5^{\circ} \pm 2.5^{\circ}$; longitude: $115.5^{\circ} \pm 1.5^{\circ}$ ) and Congo (latitude: $-4.0^{\circ} \pm 2.0^{\circ}$; longitude: $18.0^{\circ} \pm 2.0^{\circ}$ ).

The results show similar seasonal variability. However there are large differences (up to $25 \%$ ) observed during winter especially in Beijing, where the anthropogenic emissions of $\mathrm{NO}_{\mathrm{x}}$ are higher than in Congo (see Fig. 6, bottom), because the latter is mainly influenced by biogenic sources and fires. This result shows that the temperature dependence of the $\mathrm{NO}_{2}$ absorption cross-section should be taken into account in case of large tropospheric $\mathrm{NO}_{2}$ columns to limit as much as possible (seasonal dependent) systematic errors of the glyoxal column, caused by spectral interference. 

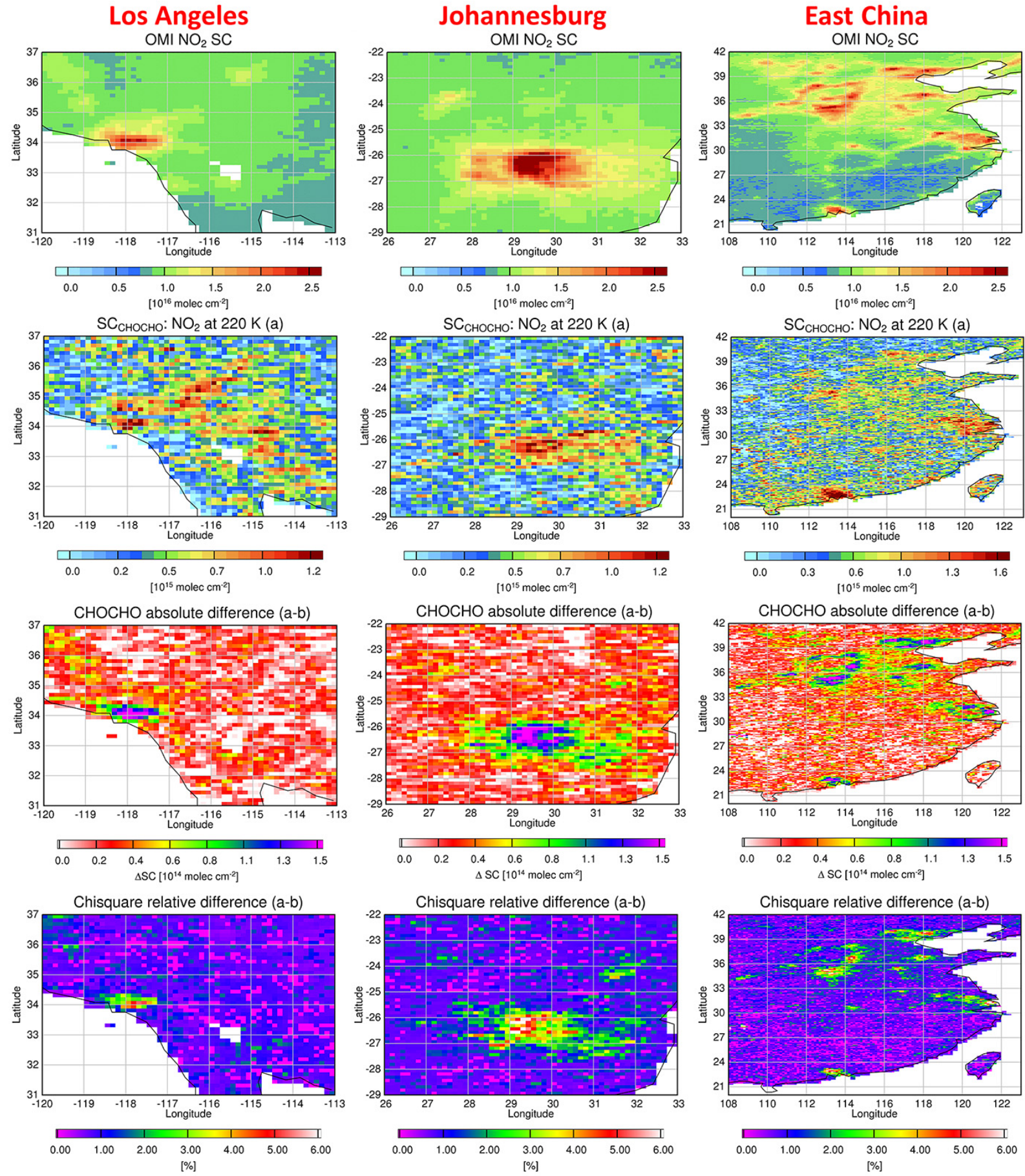

Figure 5. Monthly maps of $\mathrm{NO}_{2} \mathrm{SCs}$, glyoxal SCs, glyoxal absolute differences, and chi-square relative differences between glyoxal retrievals with and without high-temperature $\mathrm{NO}_{2}$ absorption cross-section over Los Angeles, Johannesburg, and East China for September 2007. (a) CHOCHO SCs retrieved with $220 \mathrm{KNO}_{2}$ absorption cross-section. (b) An additional $\mathrm{NO}_{2}$ absorption cross-section at high temperature $(294 \mathrm{~K})$ is included in the glyoxal retrieval.

\subsection{Dependence on the water vapour cross-section}

From ground-based observations, potential interference of water vapour with glyoxal has been identified pointing at possibly insufficient quality of existing water vapour crosssections. In some cases, measured water vapour crosssections have been used to improve the glyoxal retrieval (Sinreich et al., 2007, 2010). However, evidence for problems 


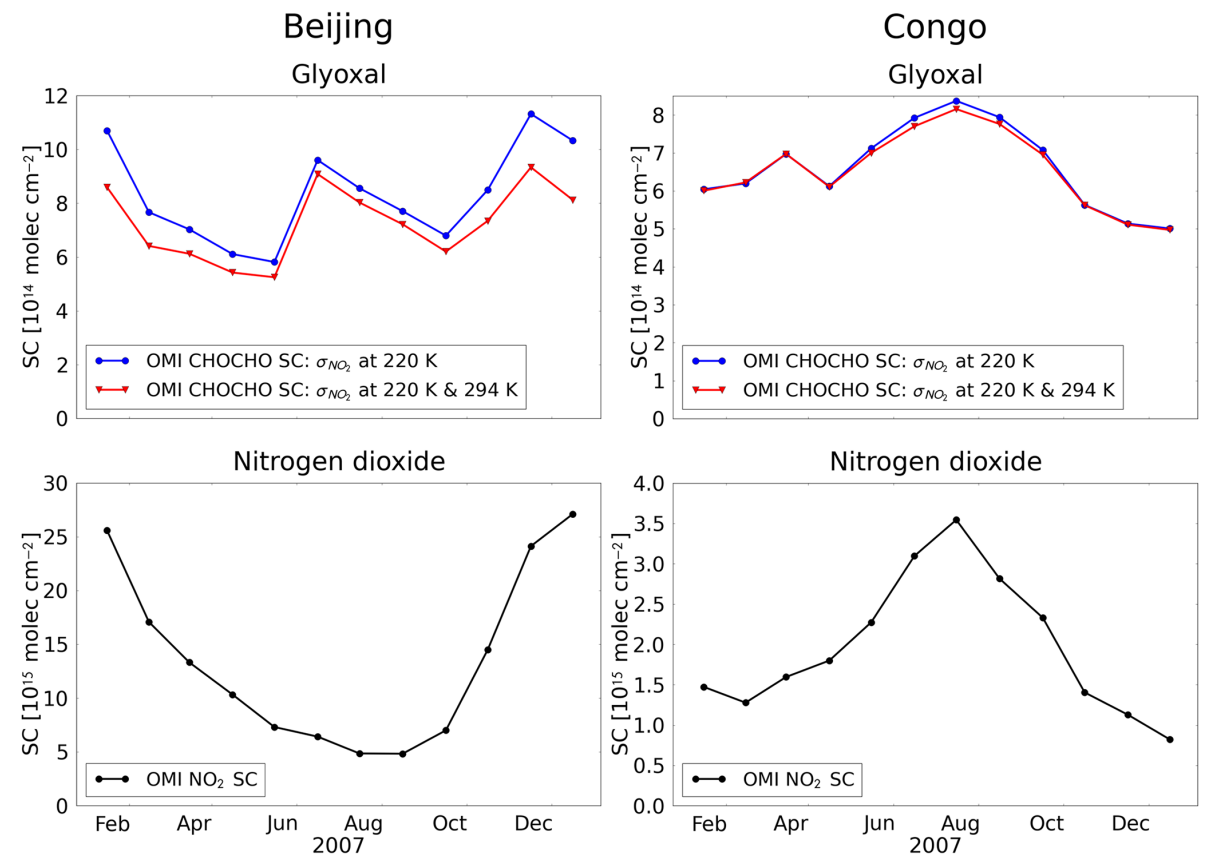

Figure 6. Seasonal variation of glyoxal SCs including and excluding the high-temperature $\mathrm{NO}_{2}$ absorption cross-section (top), and $\mathrm{NO}_{2} \mathrm{SCs}$ (bottom) over Beijing (left: latitude, $37.5^{\circ} \pm 2.5^{\circ}$; longitude, $115.5^{\circ} \pm 1.5^{\circ}$ ) and Congo (right: latitude, $-4.0^{\circ} \pm 2.0^{\circ} ;$ longitude, $18.0^{\circ} \pm 2.0^{\circ}$ ) for 2007.

Table 2. Chi-square relative difference and $P$ values from the Wilcoxon signed-rank test for five regions have been computed, using as reference water vapour cross-section the one from the HITRAN-2005 database (Rothman et al., 2005).

\begin{tabular}{lcccccc}
\hline & $\begin{array}{c}\text { Rel. diff. max. } \\
\text { (Chi-square) }\end{array}$ & $\begin{array}{c}\text { Africa } \\
P_{\text {chis }}\end{array}$ & $\begin{array}{c}\text { China } \\
P_{\text {chis }}\end{array}$ & $\begin{array}{c}\text { NA } \\
P_{\text {chis }}\end{array}$ & $\begin{array}{c}\text { Pacific } \\
P_{\text {chis }}\end{array}$ & $\begin{array}{c}\text { Desert } \\
P_{\text {chis }}\end{array}$ \\
\hline HITRAN-2008 & $2.0 \%$ & 0.395 & 0.218 & 0.350 & 0.176 & 0.350 \\
HITEMP & $-1.5 \%$ & 0.511 & 0.227 & 0.235 & 0.054 & 0.001 \\
HITRAN-2012 & $1.0 \%$ & 0.603 & 0.981 & 0.702 & 0.785 & 0.874 \\
\hline
\end{tabular}

with water vapour cross-sections in satellite observations has not been published so far. In order to evaluate the potential interference due to the choice of water vapour cross-section in the glyoxal retrieval, four different water vapour crosssections were tested in the glyoxal retrieval (i.e. Rothman et al., 2005, 2009, 2010, 2013) and the results were compared. First, the relative differences of chi-square between retrievals using the different water vapour cross-sections are computed, assuming the database HITRAN-2005 as reference. The relative differences between the glyoxalHITRAN-2005 retrieval and those using the other crosssections led to global difference no larger than $2.0 \%$ (see Table 2). A statistical test was performed to evaluate the significance in the change of chi-square. As the chi-square values are non-normally distributed, the Wilcoxon signed-rank test is used, where the null hypothesis assumes that two populations have an identical distribution at the significance level of 0.05 ( $P$ value). If the $P$ values are larger than 0.05 , the chisquare values are not significantly different in the glyoxal retrievals, and if it is smaller than 0.05 the difference is considered significant. In Table 2 , the $P$ values $\left(P_{\text {chis }}\right)$ obtained for five selected regions (Africa, China, NA, Pacific, and desert) are summarized. $P_{\text {chis }}>0.05$ for almost all regions were obtained with the exception of $P_{\text {chis }}$ over the desert between glyoxal-HITRAN-2005 and glyoxal-HITEMP retrievals, which is smaller than 0.05 . However, the chi-square values are not improved using water vapour cross-section HITEMP and also over the desert it is well known that there are interference problems due to sand reflectance. Thus, the chi-square relative differences among the different retrievals are considered not significant. Despite that, there are some differences in glyoxal SCs between retrievals, however these are rather small and to this point it is not clear which crosssection produces the correct values. For that reason, the decision was taken to use the water vapour cross-section from the HITRAN-2005 database in our retrieval. 


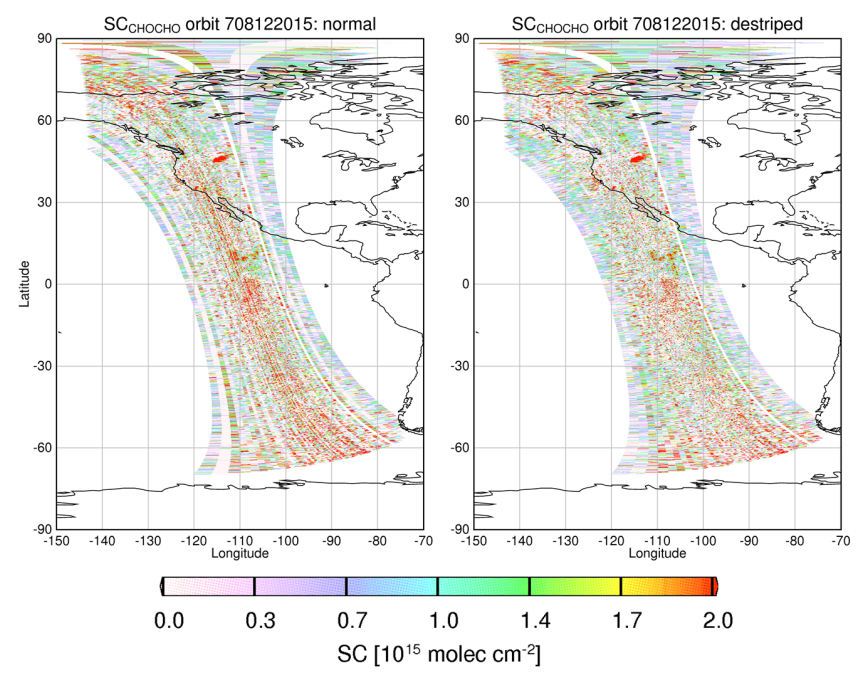

Figure 7. Glyoxal SCs retrieved from OMI data (orbit 708122015) with (right) and without (left) destriping correction.

\subsection{Destriping correction}

When comparing SCs retrieved in different viewing directions from instruments using an imaging spectrometer such as OMI, offsets are sometimes observed between viewing directions due to different sources such as small differences in the dark current correction or pixel damage. Therefore, a correction has to be applied to the OMI measurements for an optimum quality of the retrieved SCs. The approach consist of a statistical evaluation of a large data set of CHOCHO SCs over a limited region, and the assumption that the $\mathrm{CHOCHO}$ VCs do not depend on the viewing direction in that region (Boersma et al., 2007). Here, we assume that the variations in glyoxal air mass factor are small close to the equator and only correct for the change in viewing zenith angle. The median SC is computed for a number of measurements over a selected region (lat. $30^{\circ} \mathrm{N}-30^{\circ} \mathrm{S}$; long. $160^{\circ} \mathrm{E}-140^{\circ} \mathrm{W}$ ), and the mean deviation from this value for each viewing direction is computed. Then, the pattern is corrected in all SCs by adding it as an offset. In Fig. 7, an example of the destriping correction applied to an OMI orbit measured on $12 \mathrm{Au}-$ gust 2007 is shown. The corrected orbit shows a significant reduction of the stripes between the different viewing directions in comparison to the retrieval without the correction.

\subsection{Air mass factor computation}

As the SC depends on observation geometry, it is often useful to compute the vertical column which is defined as $\mathrm{VC}=$ $\int \rho_{i}(z) \mathrm{d} z$, where $\rho_{i}(z)$ is the concentration of the species and $\mathrm{d} z$ is the vertical path through the atmosphere.

The vertical and slant columns are related by the air mass factor (AMF). The AMF is defined as the ratio of SC and $\mathrm{VC}$, and depends on the radiative transfer in the atmosphere (Platt and Stutz, 2008). It depends on the trace gas profile, air pressure, surface albedo, temperature, ozone and aerosol profiles, clouds, as well as on the SZA and the measurement geometry.

In this work, AMFs have been calculated by the radiative transfer model SCIATRAN (Rozanov et al., 2005) assuming typical glyoxal profiles as described in Wittrock (2006), page 96. More sophisticated a priori data including aerosol and cloud effects are needed in the future, but improvements of AMFs are not the focus of the present study.

\subsection{Glyoxal detection limit and error}

When investigating the uncertainty of the retrieved glyoxal columns, several effects have to be taken into account. Photon-shot noise, related to the number of photons collected in a single measurement and governed by the probability distribution of incoming photons (Burrows et al., 2011), together with readout noise and the dark signal in the detector, are the main sources of random errors in the radiance measurements. Systematic errors in the slant columns are introduced by uncertainties in reference spectra, an imperfect wavelength calibration, and instrumental features (Boersma et al., 2004; De Smedt et al., 2008; Vrekoussis et al., 2009; Lerot et al., 2010). These, combined with other parameters such as the limited penetration of solar radiation due the scattering effects in the atmosphere, determine the total uncertainty of the retrieved glyoxal SCs. In this study, these systematic errors are estimated as described by Wittrock (2006) to be around $6.0 \times 10^{14}$ molec $\mathrm{cm}^{-2}$ in the SC.

In addition, the air mass factor calculations introduce more uncertainties in the results (Boersma et al., 2004) as well as the influence of clouds and aerosols, which lead to significant uncertainties in satellite retrievals (Wang et al., 2008; Vrekoussis et al., 2009).

Moreover, some offset errors can be introduced for weak absorbers in the DOAS retrieval (Wittrock, 2006). In order to account for these effects, the normalization method of columns introduced in Vrekoussis et al. (2009) has been applied, which consists in computing the mean of the slant columns over an area in the remote Pacific Ocean (lat.: $0^{\circ} \pm$ $60^{\circ}$; long.: $180^{\circ} \pm 30^{\circ}$ ), and subtracting this value from all the measurements of the same day. In order to account for the glyoxal background, a slant column of $2.0 \times 10^{14}$ molec cm $^{-2}$ is then added to the global field.

For the computation of the detection limit, the minimum glyoxal slant columns detectable with the DOAS retrieval from OMI measurements are estimated for an ideal case of a single measurement as described by Vrekoussis et al. (2009). This SC detection limit for the ideal case and a single measurement is around $1.0 \times 10^{15} \mathrm{molec} \mathrm{cm}^{-2}$ using a typical RMS for a region where high glyoxal amounts are found (indicating ideal measurement conditions; e.g. Africa; $\left.6 \times 10^{-4}\right)$. This limit is reduced by averaging over time or space to compute monthly means. 


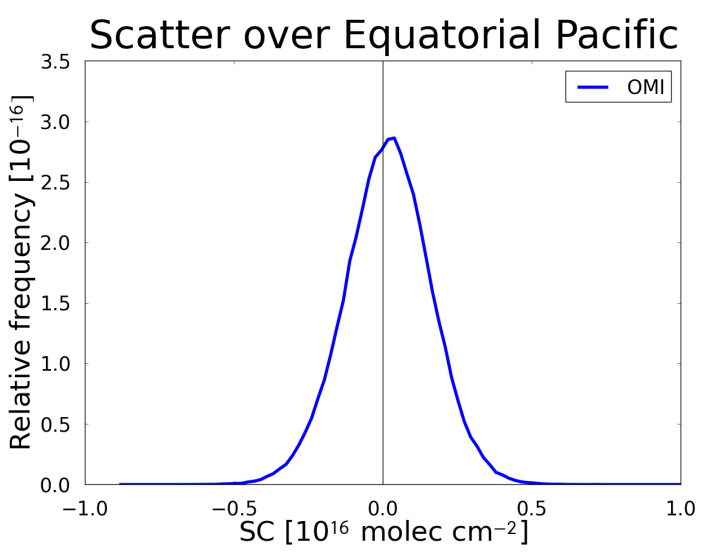

Figure 8. Distribution of $\mathrm{CHOCHO}$ SCs over a clean equatorial ocean region $\left(5^{\circ} \mathrm{S}-5^{\circ} \mathrm{N}, 160-200^{\circ} \mathrm{E}\right)$ for August 2007.

Table 3. CHOCHO retrieval settings for the instrument intercomparison.

\begin{tabular}{lccc}
\hline & This work (OMI) & GOME-2 & SCIAMACHY \\
\hline Fitting window & \multicolumn{3}{c}{$433-458 \mathrm{~nm}$} \\
Polynomial & 3 & 4 & 4 \\
Cross-sections & $\mathrm{CHOCHO} \mathrm{NO}_{2}(220 \mathrm{~K}$ and $294 \mathrm{~K})$, \\
& $\mathrm{O}_{3}\left(223 \mathrm{~K}_{2}\right), \mathrm{O}_{4}, \mathrm{H}_{2} \mathrm{O}_{\text {vap }}$, Ring \\
Liquid water & + & - & -
\end{tabular}

For comparison, the scatter of SCs over a clean region in the equatorial Pacific $\left(5^{\circ} \mathrm{S}-5^{\circ} \mathrm{N}, 160-200^{\circ} \mathrm{E}\right)$ has been computed for August 2007. As illustrated in Fig. 8, the SC scatter shows a distribution around zero with FWHM of $3.3 \times 10^{15}$ molec cm$^{-2}$ and a standard deviation of $1.4 \times$ $10^{15} \mathrm{molec}^{-2}$, which is of the same order of magnitude as obtained for the detection limit.

\section{Comparison to GOME-2 and SCIAMACHY data}

In order to evaluate the quality and consistency of the improved OMI glyoxal retrieval, a comparison with GOME2 and SCIAMACHY data has been performed using similar fitting parameters for all data sets. The only exception is the polynomial order used, which had to be adapted for each instrument, most likely due to different instrumental effects. Moreover, no liquid water correction is applied to the SCIAMACHY and GOME-2 retrievals. We therefore focus the comparison between instruments on measurements over land. Table 3 summarizes the main fitting parameters used in the glyoxal retrievals from OMI, GOME-2, and SCIAMACHY.

In order to take into account the influence of clouds on the OMI CHOCHO retrievals, a cloud screening is applied based on the OMI $\mathrm{O}_{4}$ cloud product (Acarreta et al., 2004) using a cloud threshold of $30 \%$. For GOME-2 and SCIAMACHY, a cloud screening based on the FRESCO+ is applied (Wang
Table 4. Regions selected for Fig. 9.

\begin{tabular}{lrrr}
\hline & Box No. & Latitude $\left[^{\circ}\right]$ & Longitude $\left[^{\circ}\right]$ \\
\hline N-America & 1 & $32.0 \pm 4.0$ & $-90.0 \pm 10.0$ \\
S-America-a & 2 & $0.0 \pm 10.0$ & $-62.0 \pm 8.0$ \\
S-America-b & 3 & $-2.0 \pm 4.0$ & $-50.0 \pm 3.0$ \\
W-Africa & 4 & $6.0 \pm 4.0$ & $1.0 \pm 10.0$ \\
C-Africa-a & 5 & $2.0 \pm 4.0$ & $19.0 \pm 9.0$ \\
C-Africa-b & 6 & $-7.0 \pm 5.0$ & $19.0 \pm 9.0$ \\
Indonesia & 7 & $2.0 \pm 6.0$ & $108.0 \pm 12.0$ \\
Australia & 8 & $-14.0 \pm 3.0$ & $135.0 \pm 10.0$ \\
S-China & 9 & $25.0 \pm 3.0$ & $112.0 \pm 5.0$ \\
E-China & 10 & $34.0 \pm 5.0$ & $116.0 \pm 5.0$ \\
India & 11 & $24.0 \pm 4.0$ & $85.0 \pm 7.0$ \\
Europe & 12 & $48.0 \pm 5.0$ & $7.0 \pm 6.0$ \\
\hline
\end{tabular}

et al., 2008). In addition, the destriping correction is needed only in the OMI CHOCHO retrieval.

For this comparison, we used monthly mean VCs from the GOME-2 and SCIAMACHY instruments. Briefly, SCIAMACHY and GOME-2 are nadir-viewing spectrometers providing the spectral coverage and resolution needed for DOAS retrievals of atmospheric trace gases. These instruments measure the light scattered by the atmosphere in the UV and visible range. They have a spatial resolution of $60 \mathrm{~km} \times 30 \mathrm{~km}$ and $80 \mathrm{~km} \times 40 \mathrm{~km}$, respectively. SCIAMACHY had an equator crossing time of 10:00 LT, and global coverage was achieved in 6 days, while GOME-2 has a nearly daily global coverage and an equatorial overpass time of 09:30 LT (Burrows et al., 1995; Bovensmann et al., 1999; Callies et al., 2000).

In Fig. 9 (top), time series of monthly mean $\mathrm{CHOCHO}$ VCs over 12 regions (see Table 4) are shown for the year 2007. The monthly observations are averaged within each of the areas, which represent different environments with large glyoxal production from biogenic, anthropogenic and pyrogenic sources (see Fig. 9, bottom). The seasonal variabilities of the data sets have an overall good consistency. At closer inspection, good agreement is found in the temporal behaviour among data sets over regions dominated by biogenic emissions and also over regions where large fire events occur, such as C-Africa-b. However, SCIAMACHY data are often higher than OMI and GOME-2 results. Also, the temporal variability of glyoxal over Africa and South America is less pronounced than in North America and Australia, which is possibly related to large constant emissions of vegetation in those areas. Additionally, significant differences between the products are found over regions with large anthropogenic activities (e.g. Europe, E. China). Some of the differences among the instruments could be related to the different overpass times, which sample different VOC emissions and photochemical regimes. Additional variations can be introduced by different instrumental features, and to a lesser degree the absence of liquid water correction in SCIAMACHY 

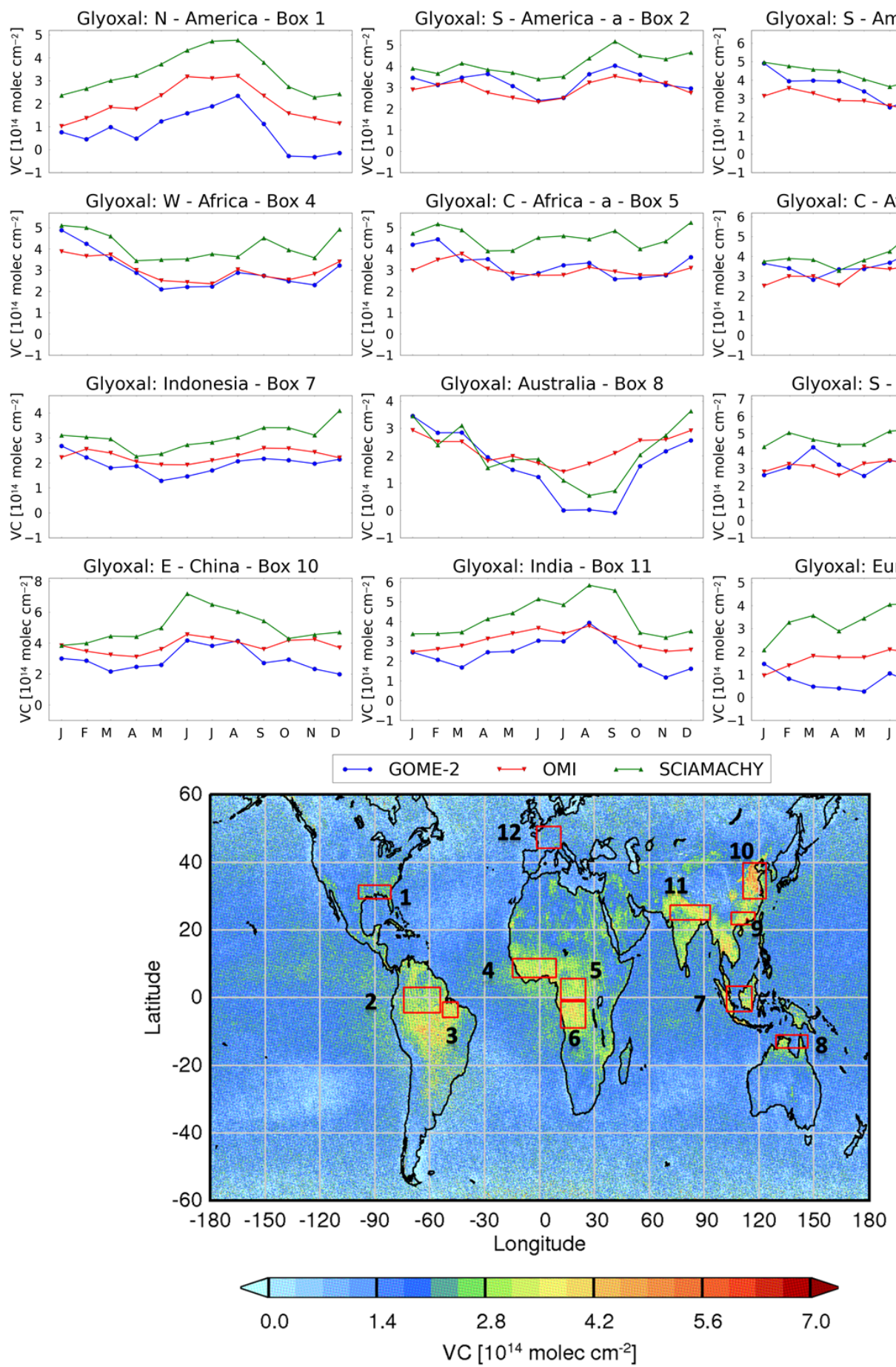

Figure 9. Comparison of monthly averaged CHOCHO VCs from OMI (red line), GOME-2 (blue line) and SCIAMACHY (green line) data for 12 selected regions (boxes 1-12) for 2007 (top). Annual global CHOCHO map with 12 selected regions for different environments (bottom).

and GOME-2 retrievals. More work on GOME-2 and SCIAMACHY data is needed to identify the origin of the observed differences.

\section{Seasonal variation}

In order to study the seasonal variability of OMI CHOCHO, maps of average CHOCHO VCs for Northern Hemispheric winter (DJF), spring (MAM), summer (JJA), and autumn 

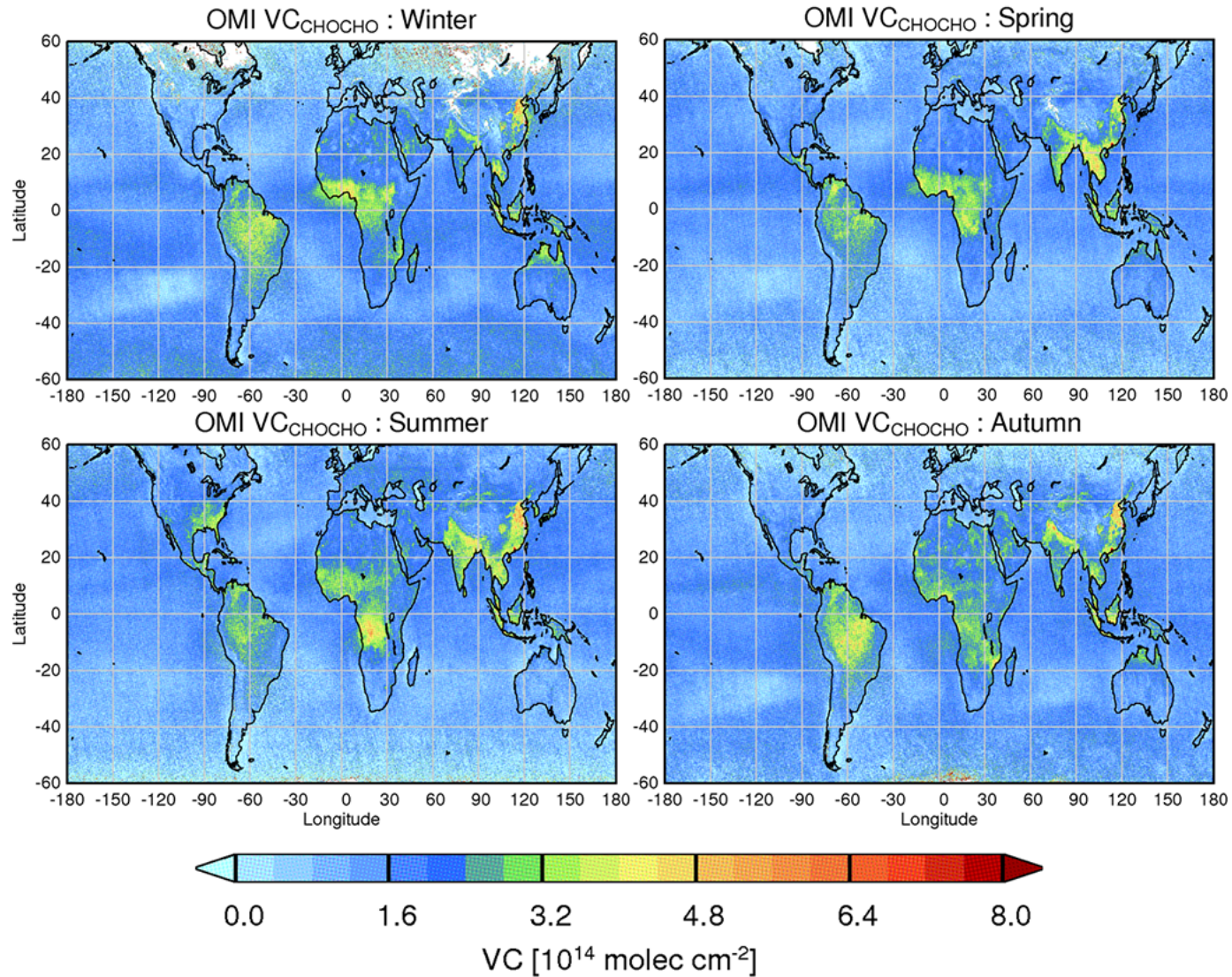

Figure 10. Seasonal means of CHOCHO VCs for winter (DJF), spring (MAM), summer (JJA), and autumn (SON) for the period $2005-2013$.
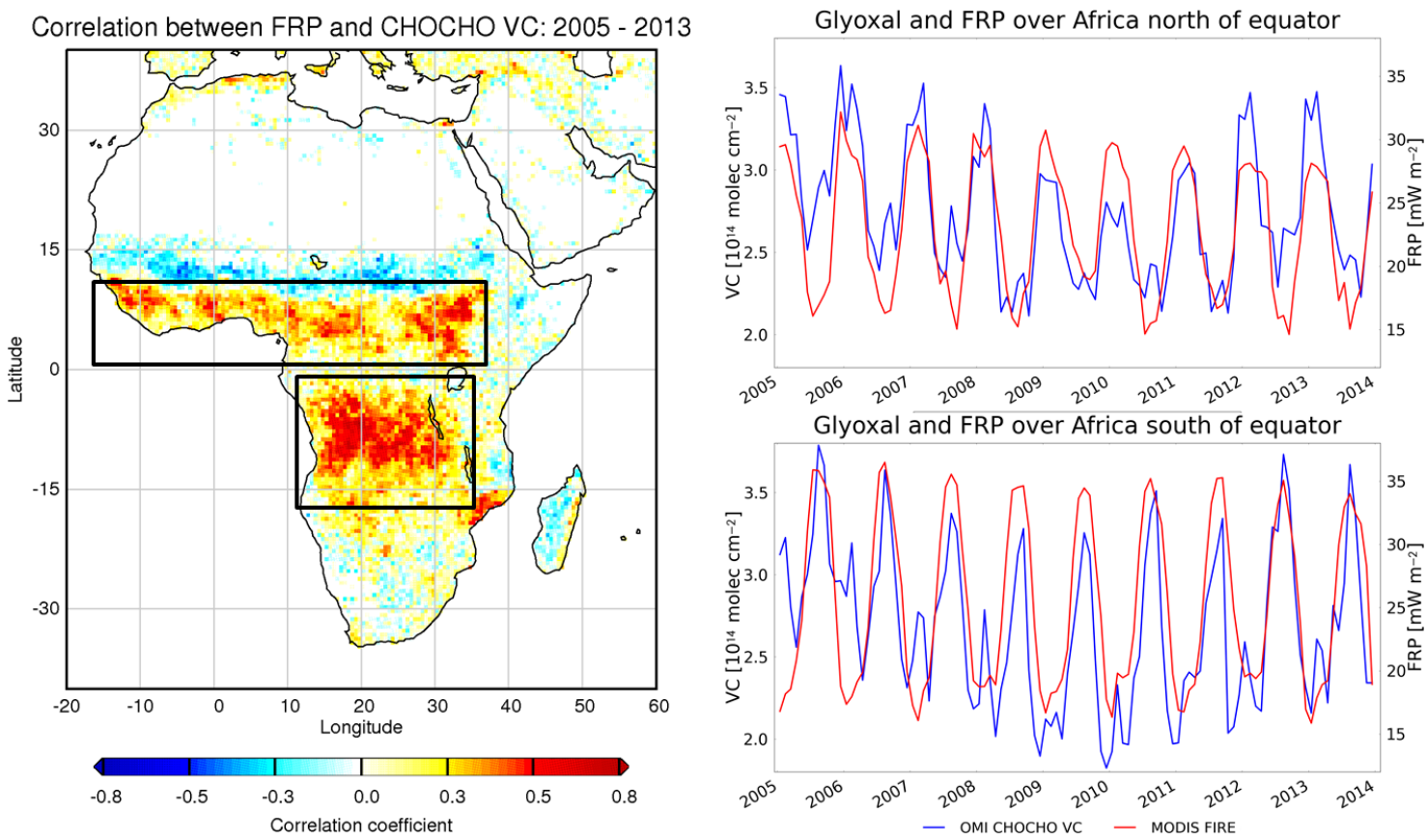

Figure 11. Pearson correlation coefficient (left) and seasonal variation (right) of FRP and CHOCHO VC over Africa from 2005 to 2013. 
(SON) are presented in Fig. 10. These are averaged for the respective seasons within the time period 2005 to 2013 . The maps show that the highest levels of $\mathrm{CHOCHO}$ are found in the tropical and sub-tropical regions. The CHOCHO VCs vary with the season, the maxima and minima corresponding to the respective summer and winter. This is consistent with the fact that the biogenic emissions increase in the warm periods and thus the $\mathrm{CHOCHO}$ production is enhanced. Whereas the largest $\mathrm{CHOCHO}$ amounts are found in Africa north of the equator in DJF, maximum CHOCHO production is observed in JJA over central Africa due to fire emissions. The maximum of $\mathrm{CHOCHO}$ in South America corresponds to SON, in agreement with the largest fire activity and the highest $\mathrm{NO}_{2}$ levels during that season (Schreier et al., 2014). Close to the equator, the CHOCHO seasonal variation is quite smooth, suggesting that $\mathrm{CHOCHO}$ is mostly produced by biogenic sources from tropical forests (Guenther et al., 2006). In contrast, $\mathrm{CHOCHO}$ from biogenic sources at higher latitudes has a clear seasonal cycle with the maximum in JJA (e.g. Southeast US), which corresponds to the vegetation growth cycle. No significant differences were found between seasons over highly populated regions (e.g. Southeast China), most likely as a result of different sources contributing to the $\mathrm{CHOCHO}$ amounts in different seasons (e.g. anthropogenic emissions in DJF, biogenic production in MAM).

\section{Glyoxal as an indicator of pyrogenic emissions}

Pyrogenic emission is one of the main sources of trace gases in the atmosphere and is estimated to contribute $18 \%$ of the global CHOCHO levels released to the atmosphere (Stavrakou et al., 2009a). Around $60 \%$ of this proportion are emitted directly by the fires and the rest by secondary production. Moreover, it is well known that large fire events occur during the warm season and mainly over continental Africa. In order to identify the regions with largest production of CHOCHO over Africa, correlation coefficients between CHOCHO VCs and fire radiative power (FRP) are presented. FRP is a measure of outgoing radiant heat from fires (in units of Watt), which can be retrieved from the MODerate resolution Imaging Spectroradiometers (MODIS) on board NASA's Terra and Aqua satellites (Justice et al., 2002). Additionally, the improved OMI CHOCHO product is used to investigate the effect of a large fire event in Russia in 2010.

\subsection{Correlation with fires over Africa}

The correlation coefficients are determined by assuming a linear relationship between CHOCHO VCs and FRP for the African continent and are illustrated in Fig. 11 (left). The calculations were performed with a grid resolution of $0.5^{\circ} \times 0.5^{\circ}$ using monthly means of OMI CHOCHO VCs and FRP from MODIS on board Aqua (MYD14CMH) (Justice
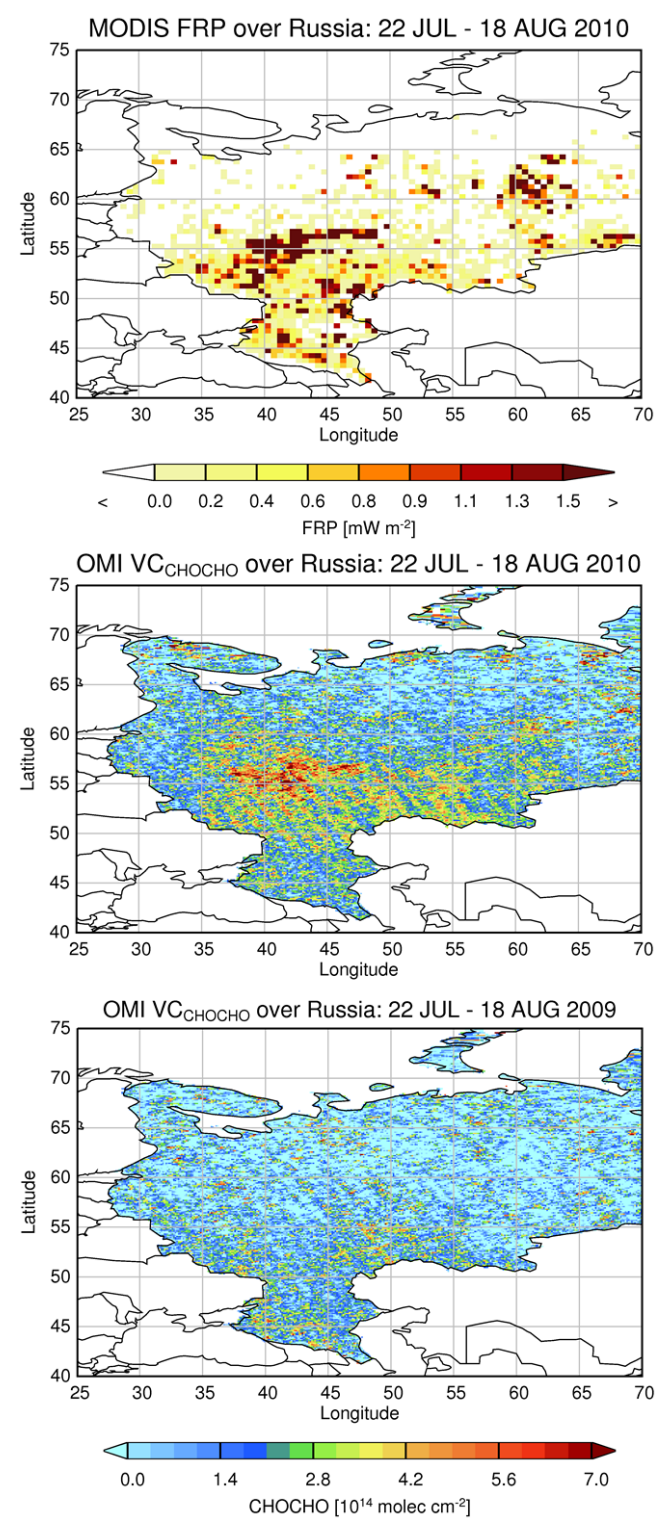

Figure 12. Maps of fire radiative power (top) and glyoxal VCs (middle) over Russia from 22 July to 18 August 2010, as well as glyoxal VCs for the same period in 2009 (bottom).

et al., 2002). A linear relationship between tropospheric $\mathrm{NO}_{2}$ VCs and FRP was already shown by Schreier et al. (2014). They demonstrated a strong link between the seasonal cycles of tropospheric $\mathrm{NO}_{2}$ and FRP for the main biomass burning regions. Also, some negative correlation coefficients are observed in Fig. 11, which correspond to regions dominated by biogenic emissions as shown in Vrekoussis et al. (2010) and thus less presence of fire activities. In this study, we found a comparable connection between $\mathrm{CHOCHO}$ and FRP for two similar regions in Africa as shown in Schreier et al. (2014). The time series of spatially averaged monthly means are shown in Fig. 11 (right) for the two regions. Although pyrogenic emissions contribute only about $18 \%$ to 
the global budget of CHOCHO (Stavrakou et al., 2009a), there clearly exist some regions where fires are the dominant source of glyoxal and where good agreement in seasonal behaviour is found with FRP. Moreover, additional peaks are observed in CHOCHO VCs during the wet season in both regions. As there is no significant fire activity during this time, these peaks are most likely caused by biogenic sources.

\subsection{Russian fires in $\mathbf{2 0 1 0}$}

In summer 2010, unprecedented temperature anomalies causing severe drought in some areas of European Russia resulted in the outbreak of many wildfires (Shvidenko et al., 2011). Beginning in mid-July, the number of fires showed a steadily increasing occurrence until the end of July, followed by a decrease in August (Parshutkina et al., 2011).

The wildfires around Moscow created elevated atmospheric levels of carbon monoxide $(\mathrm{CO}), \mathrm{NO}_{\mathrm{x}}, \mathrm{O}_{3}$, sulfur dioxide $\left(\mathrm{SO}_{2}\right)$, methane $\left(\mathrm{CH}_{4}\right)$, carbon dioxide $\left(\mathrm{CO}_{2}\right)$, ammonia $\left(\mathrm{NH}_{3}\right)$, formic acid $(\mathrm{HCOOH})$ and aerosol load, affecting air quality and human health (Yurganov et al., 2011; Elansky et al., 2011; Konovalov et al., 2011; van Donkelaar et al., 2011; R'Honi et al., 2013). Here, we show that high levels of glyoxal have also been produced from these wildfires.

For this case study, we use the $24 \mathrm{~h}$ assimilation data of FRP from the Global Fire Assimilation System (GFASv1.0) (Kaiser et al., 2012). Briefly, GFASv1.0 spatially aggregates all valid observations of fire and non-fire from the two MODIS instruments onto a horizontal resolution of $0.5^{\circ} \times$ $0.5^{\circ}$ and calculates the total FRP sums for each grid cell. Further details about the daily $24 \mathrm{~h}$ assimilated GFASv1.0 FRP product, which we use for the following analysis of Russian wildfires can be found in Kaiser et al. (2012).

The geographical distribution of the $24 \mathrm{~h}$ assimilated FRP and the tropospheric vertical columns of $\mathrm{CHOCHO}$ are shown in Fig. 12 (top and middle) for the period 22 July to 18 August 2010, which represents the main part of the fire period. The largest fire activity is observed in the east of Moscow and also corresponds to the location where highest CHOCHO VCs are found, which is a region with usually rather low glyoxal levels (see Fig. 12, bottom). This is a clear indication of glyoxal emissions from forest fires. Another hot-spot of fire activity during the selected time period is observed between $60^{\circ}$ and $65^{\circ} \mathrm{N}$ and $60^{\circ}$ and $65^{\circ} \mathrm{E}$. However, these fires are much less intense and thus, the magnitude of the observed $\mathrm{CHOCHO}$ columns is lower.

\section{Summary and conclusions}

In this study, an improved glyoxal product has been developed for OMI measurements, expanding the data set available from SCIAMACHY and GOME-2 to data taken in an afternoon orbit. Sensitivity tests on synthetic data as well as on OMI measurements over selected regions provided useful information for the selection of DOAS fitting window and the most appropriate polynomial degree for this study. Moreover, two approaches for the reduction of the liquid water interference over clear water oceans have been evaluated, finding that including the liquid water absorption crosssection in the DOAS fit leads to the best reduction of negative glyoxal values over oceans in the OMI data. For the first time, possible interferences by tropospheric $\mathrm{NO}_{2}$ over areas with large anthropogenic emissions have been investigated. A high-temperature $\mathrm{NO}_{2}$ absorption cross-section representing near-surface $\mathrm{NO}_{2}$ has been introduced in the retrieval, leading to a significant reduction of glyoxal over these areas and an improved fit quality.

Investigation of the impact of different water vapour crosssections in the fit shows that for OMI data, this does not seem to be a critical factor. This is in contrast to ground-based MAX-DOAS observations, where water vapour absorption can interfere strongly with the retrievals, in particular in the Tropics.

The comparison of OMI glyoxal with GOME-2 and SCIAMACHY data shows good overall agreement over areas with large biogenic emissions. Significant differences were found over regions with large anthropogenic emissions. Moreover, a similar seasonal behaviour is observed among the three products, although less pronounced in the OMI product. Also, systematically higher SCIAMACHY CHOCHO columns are observed in comparison to the results obtained from the other two instruments.

The new CHOCHO retrieval has been applied to identify pyrogenic activities over Africa and for the large Russian wildfires during July/August 2010. It was shown that the location and temporal pattern of the retrieved glyoxal columns is closely linked with fire radiative power observations, indicating that in these areas, pyrogenic emissions dominate the glyoxal signal.

In spite of the progress made on OMI glyoxal retrieval here, the resulting data sets are still noisy and depend critically on the details of the selections made for the retrieval. Further improvements in signal-to-noise and consistency are needed to make full use of the synergy between measurements from instruments in morning and afternoon orbits. In addition, the effects of clouds and aerosols on the air mass factors need to be taken into account, in particular for biomass burning scenarios.

Acknowledgements. L. M. A. Alvarado gratefully acknowledges funding by the German Academic Exchange Service (DAAD). We acknowledge financial support provided by the University of Bremen and the Earth System Science Research School (ESSReS), an initiative of the Helmholtz Association of German Research Centres (HGF) at the Alfred Wegener Institute for Polar and Marine Research (AWI). We want to thank Johannes Kaiser and the MACC team for providing the GFASv1.0 FRP product as well as Michel Van Roozendael and two anonymous reviewers for helpful 
comments and suggestions. OMI lv1 data have been provided by NASA. GOME-2 lv1 data have been provided by EUMETSAT. SCIAMACHY lv1 data have been provided by ESA through DLR.

Edited by: M. Van Roozendael

\section{References}

Acarreta, J. R., De Haan, J. F., and Stammes, P.: Cloud pressure retrieval using the $\mathrm{O}_{2}-\mathrm{O}_{2}$ absorption band at $477 \mathrm{~nm}$, J. Geophys. Res.-Atmos., 109, D05204, doi:10.1029/2003JD003915, 2004.

Andreae, M. O. and Merlet, P.: Emission of trace gases and aerosols from biomass burning, Global Biogeochem. Cy., 15, 955-966, doi:10.1029/2000GB001382, 2001.

Atkinson, R.: Atmospheric chemistry of VOCs and $\mathrm{NO}_{\mathrm{x}}$, Atmos. Environ., 34, 2063-2101, doi:10.1016/S1352-2310(99)00460-4, 2000.

Atkinson, R. and Arey, J.: Gas-phase tropospheric chemistry of biogenic volatile organic compounds: a review, Atmos. Environ., 37, Supplement 2, 197-219, doi:10.1016/S1352-2310(03)00391-1, 2003.

Boersma, K. F., Eskes, H. J., and Brinksma, E. J.: Error analysis for tropospheric $\mathrm{NO}_{2}$ retrieval from space, J. Geophys. Res., 109, D04311, doi:10.1029/2003JD003962, 2004.

Boersma, K. F., Eskes, H. J., Veefkind, J. P., Brinksma, E. J., van der A, R. J., Sneep, M., van den Oord, G. H. J., Levelt, P. F., Stammes, P., Gleason, J. F., and Bucsela, E. J.: Near-real time retrieval of tropospheric $\mathrm{NO}_{2}$ from OMI, Atmos. Chem. Phys., 7, 2103-2118, doi:10.5194/acp-7-2103-2007, 2007.

Bogumil, K., Orphal, J., Homann, T., Voigt, S., Spietz, P., Fleischmann, O., Vogel, A., Hartmann, M., Kromminga, H., Bovensmann, H., Frerick, J., and Burrows, J.: Measurements of molecular absorption spectra with the SCIAMACHY pre-flight model: instrument characterization and reference data for atmospheric remote-sensing in the $230-2380 \mathrm{~nm}$ region, J. Photochem. Photobiol. A, 157, 167-184, doi:10.1016/S1010-6030(03)00062-5, 2003.

Bovensmann, H., Burrows, J. P., Buchwitz, M., Frerick, J., Noël, S., Rozanov, V. V., Chance, K. V., and Goede, A. P. H.: SCIAMACHY: mission objectives and measurement modes, J. Atmos. Sci., 56, 127-150, doi:10.1175/15200469(1999)056<0127:SMOAMM>r2.0.CO;2, 1999.

Burrows, J., Hölzle, E., Goede, A., Visser, H., and Fricke, W.: SCIAMACHY - scanning imaging absorption spectrometer for atmospheric chartography, Acta Astronaut., 35, 445-451, doi:10.1016/0094-5765(94)00278-T, 1995.

Burrows, J. P., Platt, U., and Borrell, P.: Tropospheric Remote Sensing from Space, in: The Remote Sensing of Tropospheric Composition from Space, edited by: Burrows, J. P., Borrell, P., Platt, U., Guzzi, R., Platt, U., and Lanzerotti, L. J.: Physics of Earth and Space Environments, Springer, Berlin, Heidelberg, 165, 2011.

Callies, J., Corpaccioli, E., Eisinger, M., Hahne, A., and Lefebvre, A.: GOME-2 - Metop's second-generation sensor for operational ozone monitoring, ESA Bulletin, 102, 28-36, 2000.

Chance, K. and Kurucz, R.: An improved high-resolution solar reference spectrum for earth's atmosphere measurement in the ultra- violet, visible, and near infrared, J. Quant. Spectr. Radiat. Trans., 111, 1289-1295, 2010.

Curci, G., Palmer, P. I., Kurosu, T. P., Chance, K., and Visconti, G.: Estimating European volatile organic compound emissions using satellite observations of formaldehyde from the Ozone Monitoring Instrument, Atmos. Chem. Phys., 10, 11501-11517, doi:10.5194/acp-10-11501-2010, 2010.

De Smedt, I., Müller, J.-F., Stavrakou, T., van der A, R., Eskes, H., and Van Roozendael, M.: Twelve years of global observations of formaldehyde in the troposphere using GOME and SCIAMACHY sensors, Atmos. Chem. Phys., 8, 4947-4963, doi:10.5194/acp-8-4947-2008, 2008.

Elansky, N. F., Mokhov, I. I., Belikov, I. B., Berezina, E. V., Elokhov, A. S., Ivanov, V. A., Pankratova, N. V., Postylyakov, O. V., Safronov, A. N., Skorokhod, A. I., and Shumskii, R. A.: Gaseous admixtures in the atmosphere over Moscow during the 2010 summer, Izvestiya, Atmos. Ocean. Phys., 47, 672-681, doi:10.1134/S000143381106003X, 2011.

Fu, T.-M., Jacob, D. J., Wittrock, F., Burrows, J. P., Vrekoussis, M., and Henze, D. K.: Global budgets of atmospheric glyoxal and methylglyoxal, and implications for formation of secondary organic aerosols, J. Geophys. Res.-Atmos., 113, D15303, doi:10.1029/2007JD009505, 2008.

Guenther, A., Hewitt, C. N., Erickson, D., Fall, R., Geron, C., Graedel, T., Harley, P., Klinger, L., Lerdau, M., Mckay, W. A., Pierce, T., Scholes, B., Steinbrecher, R., Tallamraju, R., Taylor, J., and Zimmerman, P.: A global model of natural volatile organic compound emissions, J. Geophys. Res.-Atmos., 100, 8873-8892, doi:10.1029/94JD02950, 1995.

Guenther, A., Geron, C., Pierce, T., Lamb, B., Harley, P., and Fall, R.: Natural emissions of non-methane volatile organic compounds, carbon monoxide, and oxides of nitrogen from North America, Atmos. Environ., 34, 2205-2230, doi:10.1016/S13522310(99)00465-3, 2000.

Guenther, A., Karl, T., Harley, P., Wiedinmyer, C., Palmer, P. I., and Geron, C.: Estimates of global terrestrial isoprene emissions using MEGAN (Model of Emissions of Gases and Aerosols from Nature), Atmos. Chem. Phys., 6, 3181-3210, doi:10.5194/acp-63181-2006, 2006.

Houweling, S., Dentener, F., and Lelieveld, J.: The impact of nonmethane hydrocarbon compounds on tropospheric photochemistry, J. Geophys. Res.-Atmos., 103, 10673-10696, doi:10.1029/97JD03582, 1998.

Justice, C., Giglio, L., Korontzi, S., Owens, J., Morisette, J., Roy, D., Descloitres, J., Alleaume, S., Petitcolin, F., and Kaufman, Y.: The MODIS fire products, Remote Sens. Environ., 83, 244-262, doi:10.1016/S0034-4257(02)00076-7, 2002.

Kaiser, J. W., Heil, A., Andreae, M. O., Benedetti, A., Chubarova, N., Jones, L., Morcrette, J.-J., Razinger, M., Schultz, M. G., Suttie, M., and van der Werf, G. R.: Biomass burning emissions estimated with a global fire assimilation system based on observed fire radiative power, Biogeosciences, 9, 527-554, doi:10.5194/bg-9-527-2012, 2012.

Kansal, A.: Sources and reactivity of NMHCs and VOCs in the atmosphere: a review, J. Hazard. Mater., 166, 17-26, doi:10.1016/j.jhazmat.2008.11.048, 2009.

Konovalov, I. B., Beekmann, M., Kuznetsova, I. N., Yurova, A., and Zvyagintsev, A. M.: Atmospheric impacts of the 2010 Russian wildfires: integrating modelling and measurements of an extreme 
air pollution episode in the Moscow region, Atmos. Chem. Phys., 11, 10031-10056, doi:10.5194/acp-11-10031-2011, 2011.

Kurosu, T. P., Chance, K., Liu, X., Volkamer, R., Fu, T.-M., Millet, D., and Jacob, D. J.: Seasonally resolved global distributions of glyoxal and formaldehyde observed from the Ozone Monitoring Instrument on EOS Aura, in: Proceeding of Anais XIII Simpósio Brasileiro de Sensoriamento Remoto, 2007.

Lerot, C., Stavrakou, T., De Smedt, I., Müller, J.-F., and Van Roozendael, M.: Glyoxal vertical columns from GOME-2 backscattered light measurements and comparisons with a global model, Atmos. Chem. Phys., 10, 12059-12072, doi:10.5194/acp10-12059-2010, 2010.

Levelt, P., van den Oord, G., Dobber, M., Malkki, A., Visser, H., Vries, J. d., Stammes, P., Lundell, J., and Saari, H.: The ozone monitoring instrument, IEEE T. Geosci. Remote, 44, 1093-1101, doi:10.1109/TGRS.2006.872333, 2006

Liu, Z., Wang, Y., Vrekoussis, M., Richter, A., Wittrock, F., Burrows, J. P., Shao, M., Chang, C.-C., Liu, S.-C., Wang, H., and Chen, C.: Exploring the missing source of glyoxal (CHOCHO) over China, Geophys. Res. Lett., 39, L10812, doi:10.1029/2012GL051645, 2012.

Myriokefalitakis, S., Vrekoussis, M., Tsigaridis, K., Wittrock, F., Richter, A., Brühl, C., Volkamer, R., Burrows, J. P., and Kanakidou, M.: The influence of natural and anthropogenic secondary sources on the glyoxal global distribution, Atmos. Chem. Phys., 8, 4965-4981, doi:10.5194/acp-8-4965-2008, 2008.

Parshutkina, I. P., Sosnikova, E. V., Grishina, N. P., Stulov, E. A., Plaude, N. O., and Monakhova, N. A.: Atmospheric aerosol characterization in 2010 anomalous summer season in the Moscow region, Russ. Meteorol. Hydrol., 36, 355-361, doi:10.3103/S106837391106001X, 2011.

Platt, U. and Stutz, J.: Differential Optical Absorption Spectroscopy: Principles and Applications, Springer, 2008.

Pope, R. M. and Fry, E. S.: Absorption spectrum (380-700 nm) of pure water, II. Integrating cavity measurements, Appl. Optics, 36, 8710-8723, doi:10.1364/AO.36.008710, 1997.

R'Honi, Y., Clarisse, L., Clerbaux, C., Hurtmans, D., Duflot, V., Turquety, S., Ngadi, Y., and Coheur, P.-F.: Exceptional emissions of $\mathrm{NH}_{3}$ and $\mathrm{HCOOH}$ in the 2010 Russian wildfires, Atmos. Chem. Phys., 13, 4171-4181, doi:10.5194/acp-13-41712013, 2013.

Richter, A., Begoin, M., Hilboll, A., and Burrows, J. P.: An improved NO2 retrieval for the GOME-2 satellite instrument, Atmos. Meas. Tech., 4, 1147-1159, doi:10.5194/amt-4-1147-2011, 2011.

Rothman, L., Jacquemart, D., Barbe, A., Chris Benner, D., Birk, M., Brown, L., Carleer, M., Chackerian Jr., C., Chance, K., Coudert, L., Dana, V., Devi, V., Flaud, J.-M., Gamache, R., Goldman, A., Hartmann, J.-M., Jucks, K., Maki, A., Mandin, J.Y., Massie, S., Orphal, J., Perrin, A., Rinsland, C., Smith, M., Tennyson, J., Tolchenov, R., Toth, R., Vander Auwera, J., Varanasi, P., and Wagner, G.: The HITRAN 2004 molecular spectroscopic database, J. Quant. Spectrosc. Ra., 96, 139-204, doi:10.1016/j.jqsrt.2004.10.008, 2005.

Rothman, L., Gordon, I., Barbe, A., Benner, D., Bernath, P., Birk, M., Boudon, V., Brown, L., Campargue, A., Champion, J.-P., Chance, K., Coudert, L., Dana, V., Devi, V. Fally, S., Flaud, J.-M., Gamache, R., Goldman, A., Jacquemart, D., Kleiner, I., Lacome, N., Lafferty, W., Mandin, J.-Y.,
Massie, S., Mikhailenko, S., Miller, C., Moazzen-Ahmadi, N., Naumenko, O., Nikitin, A., Orphal, J., Perevalov, V., Perrin, A., Predoi-Cross, A., Rinsland, C., Rotger, M., Šimečková, M., Smith, M., Sung, K., Tashkun, S., Tennyson, J., Toth, R., Vandaele, A., and Vander Auwera, J.: The HITRAN 2008 molecular spectroscopic database, J. Quant. Spectrosc. Ra., 110, 533-572, doi:10.1016/j.jqsrt.2009.02.013, 2009.

Rothman, L., Gordon, I., Barber, R., Dothe, H., Gamache, R., Goldman, A., Perevalov, V., Tashkun, S., and Tennyson, J.: HITEMP, the high-temperature molecular spectroscopic database, J. Quant. Spectrosc. Ra., 111, 2139-2150, doi:10.1016/j.jqsrt.2010.05.001, 2010.

Rothman, L., Gordon, I., Babikov, Y., Barbe, A., Chris Benner, D., Bernath, P., Birk, M., Bizzocchi, L., Boudon, V., Brown, L., Campargue, A., Chance, K., Cohen, E., Coudert, L., Devi, V., Drouin, B., Fayt, A., Flaud, J.-M., Gamache, R., Harrison, J., Hartmann, J.-M., Hill, C., Hodges, J., Jacquemart, D., Jolly, A., Lamouroux, J., Le Roy, R., Li, G., Long, D., Lyulin, O., Mackie, C., Massie, S., Mikhailenko, S., Müller, H., Naumenko, O., Nikitin, A., Orphal, J., Perevalov, V., Perrin, A., Polovtseva, E., Richard, C., Smith, M., Starikova, E., Sung, K.,Tashkun, S., Tennyson, J.,Toon, G., Tyuterev, Vl., and Wagner, G.: The HITRAN 2012 molecular spectroscopic database, J. Quant. Spectrosc. Ra., 130, 4-50, doi:10.1016/j.jqsrt.2013.07.002, 2013.

Rozanov, A., Rozanov, V., Buchwitz, M., Kokhanovsky, A., and Burrows, J.: SCIATRAN 2.0 - a new radiative transfer model for geophysical applications in the $175-2400 \mathrm{~nm}$ spectral region, Adv. Space Res., 36, 1015-1019, doi:10.1016/j.asr.2005.03.012, 2005.

Rozanov, V., Rozanov, A., Kokhanovsky, A., and Burrows, J.: Radiative transfer through terrestrial atmosphere and ocean: software package SCIATRAN, J. Quant. Spectrosc. Ra., 133, 13-71, doi:10.1016/j.jqsrt.2013.07.004, 2013.

Schreier, S. F., Richter, A., Kaiser, J. W., and Burrows, J. P.: The empirical relationship between satellite-derived tropospheric $\mathrm{NO}_{2}$ and fire radiative power and possible implications for fire emission rates of $\mathrm{NO}_{\mathrm{x}}$, Atmos. Chem. Phys., 14, 2447-2466, doi:10.5194/acp-14-2447-2014, 2014.

Setokuchi, O.: Trajectory calculations of $\mathrm{OH}$ radical- and $\mathrm{Cl}$ atom-initiated reaction of glyoxal: atmospheric chemistry of the HC(O)CO radical, Phys. Chem. Chem. Phys., 13, 6296-6304, doi:10.1039/C0CP01942A, 2011.

Shvidenko, A. Z., Shchepashchenko, D. G., Vaganov, E. A., Sukhinin, A. I., Maksyutov, S. S., McCallum, I., and Lakyda, I. P.: Impact of wildfire in Russia between 1998-2010 on ecosystems and the global carbon budget, Dokl. Earth Sci., 441, 1678-1682, doi:10.1134/S1028334X11120075, 2011.

Sinreich, R., Volkamer, R., Filsinger, F., Frieß, U., Kern, C., Platt, U., Sebastián, O., and Wagner, T.: MAX-DOAS detection of glyoxal during ICARTT 2004, Atmos. Chem. Phys., 7, 1293 1303, doi:10.5194/acp-7-1293-2007, 2007.

Sinreich, R., Coburn, S., Dix, B., and Volkamer, R.: Ship-based detection of glyoxal over the remote tropical Pacific Ocean, Atmos. Chem. Phys., 10, 11359-11371, doi:10.5194/acp-1011359-2010, 2010.

Stavrakou, T., Müller, J.-F., De Smedt, I., Van Roozendael, M., Kanakidou, M., Vrekoussis, M., Wittrock, F., Richter, A., and Burrows, J. P.: The continental source of glyoxal estimated by the 
synergistic use of spaceborne measurements and inverse modelling, Atmos. Chem. Phys., 9, 8431-8446, doi:10.5194/acp-98431-2009, 2009a.

Stavrakou, T., Müller, J.-F., De Smedt, I., Van Roozendael, M., van der Werf, G. R., Giglio, L., and Guenther, A.: Evaluating the performance of pyrogenic and biogenic emission inventories against one decade of space-based formaldehyde columns, Atmos. Chem. Phys., 9, 1037-1060, doi:10.5194/acp-9-1037-2009, $2009 b$.

Tadić, J., Moortgat, G. K., and Wirtz, K.: Photolysis of glyoxal in air, J. Photoch. Photobio. A, 177, 116-124, doi:10.1016/j.jphotochem.2005.10.010, 2006.

Thalman, R. and Volkamer, R.: Temperature dependent absorption cross-sections of O2-O2 collision pairs between 340 and $630 \mathrm{~nm}$ and at atmospherically relevant pressure, Phys. Chem. Chem. Phys., 15, 15371-15381, doi:10.1039/C3CP50968K, 2013.

Vandaele, A., Hermans, C., Simon, P., Carleer, M., Colin, R., Fally, S., Mérienne, M., Jenouvrier, A., and Coquart, B.: Measurements of the $\mathrm{NO}_{2}$ absorption cross-section from $42000 \mathrm{~cm}^{-1}$ to $10000 \mathrm{~cm}^{-1}(238-1000 \mathrm{~nm})$ at $220 \mathrm{~K}$ and $294 \mathrm{~K}$, J. Quant. Spectrosc. Ra., 59, 171-184, doi:10.1016/S0022-4073(97)00168-4, 1998.

van Donkelaar, A., Martin, R. V., Levy, R. C., da Silva, A. M., Krzyzanowski, M., Chubarova, N. E., Semutnikova, E., and Cohen, A. J.: Satellite-based estimates of ground-level fine particulate matter during extreme events: a case study of the Moscow fires in 2010, Atmos. Environ., 45, 6225-6232, doi:10.1016/j.atmosenv.2011.07.068, 2011.

Vogel, L., Sihler, H., Lampel, J., Wagner, T., and Platt, U.: Retrieval interval mapping: a tool to visualize the impact of the spectral retrieval range on differential optical absorption spectroscopy evaluations, Atmos. Meas. Tech., 6, 275-299, doi:10.5194/amt6-275-2013, 2013.

Volkamer, R., Molina, L. T., Molina, M. J., Shirley, T., and Brune, W. H.: DOAS measurement of glyoxal as an indicator for fast VOC chemistry in urban air, Geophys. Res. Lett., 32, L08806, doi:10.1029/2005GL022616, 2005a.

Volkamer, R., Spietz, P., Burrows, J., and Platt, U.: Highresolution absorption cross-section of glyoxal in the UV-vis and IR spectral ranges, J. Photochem. Photobiol. A, 172, 35-46, doi:10.1016/j.jphotochem.2004.11.011, 2005b.
Volkamer, R., San Martini, F., Molina, L. T., Salcedo, D., Jimenez, J. L., and Molina, M. J.: A missing sink for gas-phase glyoxal in Mexico City: Formation of secondary organic aerosol, Geophys. Res. Lett., 34, L19807, doi:10.1029/2007GL030752, 2007.

Vountas, M., Rozanov, V., and Burrows, J.: Ring effect: impact of rotational Raman scattering on radiative transfer in earth's atmosphere, J. Quant. Spectrosc. Ra., 60, 943-961, doi:10.1016/S0022-4073(97)00186-6, 1998.

Vrekoussis, M., Wittrock, F., Richter, A., and Burrows, J. P.: Temporal and spatial variability of glyoxal as observed from space, Atmos. Chem. Phys., 9, 4485-4504, doi:10.5194/acp-9-44852009, 2009.

Vrekoussis, M., Wittrock, F., Richter, A., and Burrows, J. P.: GOME-2 observations of oxygenated VOCs: what can we learn from the ratio glyoxal to formaldehyde on a global scale?, Atmos. Chem. Phys., 10, 10145-10160, doi:10.5194/acp-1010145-2010, 2010.

Wang, P., Stammes, P., van der A, R., Pinardi, G., and van Roozendael, M.: FRESCO+: an improved $\mathrm{O}_{2}$ A-band cloud retrieval algorithm for tropospheric trace gas retrievals, Atmos. Chem. Phys., 8, 6565-6576, doi:10.5194/acp-8-6565-2008, 2008.

Williams, J.: Organic trace gases in the atmosphere: an overview, Environ. Chem., 1, 125-136, doi:10.1071/EN04057, 2004.

Wittrock, F.: The retrieval of oxygenated volatile organic compounds by remote sensing techniques, Ph.D. thesis, University of Bremen, 2006.

Wittrock, F., Richter, A., Oetjen, H., Burrows, J. P., Kanakidou, M., Myriokefalitakis, S., Volkamer, R., Beirle, S., Platt, U., and Wagner, T.: Simultaneous global observations of glyoxal and formaldehyde from space, Geophys. Res. Lett., 33, L16804, doi:10.1029/2006GL026310, 2006.

Yu, S.: Role of organic acids (formic, acetic, pyruvic and oxalic) in the formation of cloud condensation nuclei $(\mathrm{CCN})$ : a review, Atmos. Res., 53, 185-217, doi:10.1016/S0169-8095(00)000375, 2000 .

Yurganov, L. N., Rakitin, V., Dzhola, A., August, T., Fokeeva, E., George, M., Gorchakov, G., Grechko, E., Hannon, S., Karpov, A., Ott, L., Semutnikova, E., Shumsky, R., and Strow, L.: Satellite- and ground-based CO total column observations over 2010 Russian fires: accuracy of top-down estimates based on thermal IR satellite data, Atmos. Chem. Phys., 11, 7925-7942, doi:10.5194/acp-11-7925-2011, 2011. 